\title{
Numerical Investigation on Influential Factors for Quality of Smooth Blasting in Rock Tunnels
}

\author{
Baoping Zou, ${ }^{1,2,3}$ Zhipeng Xu $\mathbb{D D}^{4}{ }^{4}$ Jianxiu Wang, ${ }^{2}$ Zhanyou Luo, ${ }^{1}$ and Lisheng $\mathrm{Hu}^{5}$ \\ ${ }^{1}$ School of Civil Engineering and Architecture, Zhejiang University of Science and Technology, Hangzhou 310023, China \\ ${ }^{2}$ Department of Geotechnical Engineering, Tongii University, Shanghai 200092, China \\ ${ }^{3}$ State Key Laboratory for Geomechanics and Deep Underground Engineering, China University of Mining and Technology, \\ Beijing, China \\ ${ }^{4}$ College of Water Resource \& Hydropower, Sichuan University, Chengdu 610065, Sichuan, China \\ ${ }^{5}$ China Railway No. 2 Engineering Group Co., Ltd., Chengdu 610065, China
}

Correspondence should be addressed to Zhipeng Xu; zpxu2018@126.com

Received 22 December 2019; Revised 23 July 2020; Accepted 25 August 2020; Published 7 September 2020

Academic Editor: Li Li

Copyright (c) 2020 Baoping Zou et al. This is an open access article distributed under the Creative Commons Attribution License, which permits unrestricted use, distribution, and reproduction in any medium, provided the original work is properly cited.

The quality of smooth blasting including the volume of over-/underbreak and blasting-induced damage of surrounding rocks has been extensively considered to be highly correlated to both the cost and advancement rate of rock tunnelling excavated by the drill-blast method. A general control strategy for smooth blasting is too difficult to be available due to the uncertainties and complexity of rock masses, as well as the varying blasting operations. As prerequisite for the evaluation of the blasting quality, effective identification of the influential factors affecting smooth blasting usually plays a significant role in the improvement of smooth blasting design. Compared to the expensive and time-consuming experiments including physical modelling and field tests, numerical modelling, as a cost-efficient approach, offers an attractive alternative to investigate the influential factors in terms of weight, which might be more applicable and reliable for the optimization of smooth blasting parameters. In this case, the dominant factors and secondary factors can be quantitatively identified. Considering the dominant factors often orient the development of things; in this work, a numerical-based approach was proposed to quantitatively identify the dominant factors influencing the quality of smooth blasting. Proposed 3-dimensional blasting modelling was based on LS-DYNA to simulate the occurrence of smooth blasting in rock masses, and the erosion algorithm was also employed to determine the fracturing of jointed rocks. The orthogonal experimental design method was utilized to optimize the experimental arrangement. Seven factors with 4 levels including the perimeter hole spacing, line of least resistance, charge concentration, charging explosive, type of rock mass, detonation velocity, and drilling deviation were taken into account. The geological setting and project background of a real rock tunnel served for the Chengdu-Chongqing high-speed railway were selected as the site conditions to perform the numerical investigation. Calculated area and distance of overbreak as the observed parameters indicating the quality of smooth blasting were utilized to determine sensitivities of factors based on the range analysis of orthogonal experiments. The results suggested that the type of rock mass has the greatest influence on the blasting quality, whereas the charge concentration and detonation velocity can be considered as the secondary factors under the specific site conditions. The proposed numerical approach for assessing influential factors of quality of smooth blasting under specified geological conditions is expected to improve the parameter design and operation of smooth blasting in practical applications.

\section{Introduction}

The drill-blast method has been extensively applicable in rock tunnelling owing to its flexibility and compatibility under complicated geological conditions. In the case of drill- blast excavation, the opening tunnel contour and damage caused by blasting will affect not only the cost and advancement rate of tunnelling but also the stability of surrounding rocks [1-4]. In view of this, the smooth blasting technique, as a protective controlled blasting method, has 
been increasingly employed to minimize the magnitude of overbreak or underbreak and thus to reduce the blastinginduced cracking in the surrounding rock masses $[5,6]$. Although the blasting quality has been significantly improved by using smooth blasting, it still inevitably caused some overbreak or underbreak which might adversely affect the safety, stability, and budget-related concerns [7-9]. Consequently, effective identification of the influential factors, especially the dominant ones, becomes quite constructive to evaluate the quality of blasting, and thus to further improve the smooth blast design with arbitrary geological conditions [10].

However, the task of quality evaluation of smooth blasting is highly challenging due to the complicated site conditions and varying blasting operations. A literature review on blasting quality evaluation reveals that most research studies focused on the overbreak or underbreak evaluation, rock damage, and ground vibration assessment, as well as the blasting control [3, 8, 11-17], which might considerably deteriorate the physical and mechanical properties of surrounding rock masses, and thus result in safety or stability concerns and overbudget, as well as construction delay. To our knowledge, however, estimation of blasting-induced damage can be considered as the most important issue in analyzing quality of smooth blasting. It is reported that most of the available evaluation methods are just based on very few cases or laboratory tests which might be just applicable to limited range of rock masses $[8,18]$. Saiang and Nordlund [19] conducted a numerical parametric study to question the effect caused by the presence of the blasting-induced damages on distribution and magnitudes of boundary stresses and ground deformation. Ramulu et al. [20] developed a damage model to evaluate the effect of repeated blasting loading on rock damages and suggested that the far-field damage should be taken into account in underground tunnelling works. Cui [21] investigated the stability of surrounding rocks and displacement at the tunnel crown caused by water-silt blasting. Benselama et al. [22] developed a correlation between the transition distance, explosive charge's weight, material, and the geometry of the propagating domain by numerical modelling under various blasting parameters. Hamdi et al. [23] studied the tensile damage of rocks under blasting via image processing techniques. Zhao et al. [24] conducted numerical simulations of typical parallel hole cut blasting by discontinuous deformation analysis (DDA), and the dynamic responses of the rock mass were assessed under different influential factors. Fan et al. [25] simulated the propagation of stress waves through fractured rock mass under blast loading using the numerical manifold method (NMM). Recently, Liu and Liu [10] developed a genetic algorithm (GA) and improved support vector regression (ISVR) coupling algorithm to establish the relationship between the geological conditions and the parameters of smooth blasting, and thus, the optimization of smooth blasting parameters was expected to be achieved using the proposed nonlinear mapping ISVR model. The results indicated that the volume of overbreak or underbreak can be considered as one of the primary indicators representing the quality of smooth blasting, and the proposed numerical-based modelling approach was applicable and reliable to optimize the smooth blast parameters. Although several influential factors were taken into account, it can be found that most of the previous studies did not focus on the importance of each factor and lack in-depth insight into the quantitative evaluation of the influences of different factors on smooth blasting. Furthermore, 2-dimensional modelling-based approaches might not offer a full understanding on the relationship between rock damage and smooth blasting parameters. On the contrary, more attention was paid to the qualitative estimation rather than quantitative assessment in evaluation of quality of smooth blasting, and the majority of proposed methods and models is just applicable to specific geological conditions which severely limited their applications and reliabilities. However, the general solution suitable for all evaluations of smooth blasting quality under various conditions is still not available. It is acknowledged that various influential factors might have different impacts on things, and the dominant factors which will control the development of things should be paid more attention. Thus, development of a quantitative method for evaluating the influential factors of quality of smooth blasting is vitally significant to well understand the impacts of these factors. Taking the flexibility and economical efficiency of numerical modelling into account, the purpose of this study is to develop a numerical-based approach for quantitative evaluation of the influential factors affecting the quality of smooth blasting. Instead of expensive and inefficient field/laboratory tests, cost-effective numerical experiments are conducted to investigate the rock behavior and dynamic responses under blasting loading on the basis of 3-dimensional modelling, and thus to assess the sensitivity of the influential factors.

In this work, the LS-DYNA code and erosion algorithm were coupled to perform the $3 \mathrm{D}$ numerical investigation under the geological setting and project background of a real rock tunnel served for Chengdu-Chongqing high-speed railway. In order to optimize the experimental conditions and reduce the times of investigations, the orthogonal experimental design method was utilized. On the basis of range analysis, calculated area and distance of over-/underbreak were predefined as the observed parameters that indicate the quality of blasting to determine the sensitivity of the factors. Proposed numerical approach is expected to improve both design and operation of smooth blasting parameters in practical applications.

\section{Numerical Experimental Approach}

2.1. Orthogonal Design. In general, the quality of smooth blasting in rock tunnelling always depends on various factors including the perimeter hole spacing, least resistance line, and charge concentration. For full understanding of all possible effects caused by these factors, full factorial design might be the best candidate for experimental arrangement. However, the full factorial design is always time-consuming, laborious, and inefficient, owing to the large sample size which grows exponentially with the number of factors $[26,27]$. Considering the efficiency and reliability, the 
orthogonal method, as one of the cost-effective experimental design methods, was employed to optimize the arrangement of numerical experiments to be conducted.

The influential factors involved in this investigation include peripheral hole spacing $E(\mathrm{~cm})$, line of least resistance $W(\mathrm{~cm})$, charge concentration $H$ (i.e., $H=E / W)$, charging explosive $D(\mathrm{~kg} / \mathrm{m})$, type of rock mass $T$, detonation velocity $V(\mathrm{~m} / \mathrm{s})$, and drilling deviation $M$. The observed parameters of the numerical investigation are determined by the characteristic parameters that represent the quality of smooth blasting, i.e., area and distance of over-/underbreaks.

2.2. Damage Modelling. Rock damage modelling is virtually associated with the dynamic behavior of rocks under blasting loading. The dynamic mechanical behavior of brittle materials such as concrete and rocks, in most cases, could be described by the Holmquist-Johnson-Cook (HJC) model, Riedel-Hiermaier-Thoma (RHT) model, Taylor-Chen-Kuszmaul (TCK) model, continuous smooth cap (CSC) model, and the Karagozian-Case (K-C) model [28]. Moreover, Cardu et al. [29] utilized the blast damage index (BDI) criterion to evaluate the stability of a rock slope under blasting. For LS-DYNA 3D, the Johnson_Holmquist_concrete (HJC) model is considered to be applicable to rock and concrete materials under large deformation and high strain rate [30]. In this work, the HJC model, as the damage model of rock blasting, is employed to describe the dynamic behavior of rock masses. The damage model HJC focuses more on interactions and heterogeneity than the traditional elastic and fracture models [31]. It can well interpret the dynamic responses of rocks under blast loading, and the results obtained using the HJC model agreed well with those of laboratory investigations [31]. For the HJC model, the evolution of stress vs. strain can be described as equation (1). The yield surface is illustrated in Figure 1(a) [30].

$$
\sigma^{*}=\left[A(1-D)+B P^{* N}\right]\left(1+C \ln \dot{\varepsilon}^{*}\right),
$$

where $\sigma^{*}=\sigma / f_{c}, \sigma$ represents the stress, $f_{c}$ is the uniaxial compressive strength under static loading, $A$ denotes the normalized cohesion strength, $D$ is the damage factor, $B$ indicates the dimensionless pressure hardening coefficient, dimensionless pressure $P^{*}=\left(P / f_{c}\right), P$ represents the actual pressure, $C$ denotes the strain rate coefficient, $N$ refers to the pressure hardening index, and the dimensionless strain rate $\dot{\mathcal{\varepsilon}}^{*}=\left(\dot{\varepsilon} / \dot{\varepsilon}_{0}\right) ; \dot{\varepsilon}$ is the actual strain rate, and $\dot{\varepsilon}_{0}$ is the reference strain rate.

The damage factor $D(0 \leq D \leq 1)$ is defined as the sum of the equivalent plastic strain and plastic volumetric strain, as shown in equation (2) and Figure 1(b):

$$
D=\sum \frac{\Delta \varepsilon_{p}+\Delta \mu_{p}}{\varepsilon_{p}^{f}+\mu_{p}^{f}},
$$

where $\Delta \varepsilon_{p}$ is the increment of equivalent plastic strain, $\Delta \mu_{p}$ denotes the increment of plastic volumetric strain, and $\quad \varepsilon_{p}^{f}+\mu_{p}^{f}=D_{1}\left(P^{*}+T^{*}\right)^{D_{2}}=f(P) \geq E F_{\mathrm{MIN}}$, which represents the plastic strain when the material is finally fractured at constant pressure $P$. The parameter $E F_{\text {MIN }}$ is the amount of plastic strain before fracture. $D 1$ and $D 2$ are the damage constants, respectively.

The relationship between the hydrostatic pressure and the volumetric strain of the rock and concrete is expressed by the segmental state equation shown in Figure 1(c). Stage $O A$ describes the linear elastic stage when $p<p_{c}$, and both loading section and unloading section can be expressed by

$$
p=K_{e} \mu
$$

where $K_{e}$ is the bulk modulus and $p_{c}$ and $\mu_{c}$ are the crushing pressure and crushing volumetric strain in the uniaxial compressive experiment, respectively.

Stage $A B$ is a plastic transition stage during which $p_{c} \leq p<p_{l}$, and plastic deformation occurs as the voids of concrete are compressed.

Loading section:

$$
p=p_{l}+\frac{\left(p_{l}-p_{c}\right)\left(\mu-\mu_{l}\right)}{\mu_{l}-\mu_{c}},
$$

where $p_{l}$ is the locking pressure and $\mu_{l}$ is the locking volumetric strain.

Unloading section:

$$
\begin{aligned}
p-p_{\max } & =\left[(1-F) K_{e}+F K_{l}\right]\left(\mu-\mu_{\max }\right), \\
F & =\frac{\mu_{\max }-\mu_{c}}{\mu_{l}-\mu_{c}},
\end{aligned}
$$

where $K_{l}$ is the plastic volumetric modulus and $p_{\max }$ and $\mu_{\max }$ are the maximum volumetric pressure and volumetric strain before unloading in which the holes of the concrete and rock are expelled, and damage occurs accompanied by cracks.

Stage $B C$ is a fully compacted stage during which $p>p_{l}$; when the pressure reaches $p_{l}$, the holes are crushed completely. The relationship between $p$ and $\mu$ is represented by a cubic polynomial.

Loading section:

$$
\begin{aligned}
& p=K_{1} \bar{\mu}+K_{2} \bar{\mu}^{2}+K_{3} \bar{\mu}^{3}, \\
& \bar{\mu}=\frac{\mu-\mu_{L}}{1+\mu_{L}}
\end{aligned}
$$

where $\bar{\mu}$ is the amended volumetric strain and $K_{1}, K_{2}$, and $K_{3}$ are constants.

Unloading section:

$$
p-p_{\max }=K_{l}\left(\bar{\mu}-\bar{\mu}_{\max }\right) .
$$

There is no hole in this stage, and the concrete and rock are crushed completely.

The joints in rock masses are modeled using the bilinear kinematic model in LS-DYNA. This model is increasingly employed in joint modelling due to the small number of parameters involved in the model, and thus, it is easy to use [32]. In this work, blasting loading is produced by the highperformance explosives. The evolution of the pressure generated in the process of blasting can be described by the 


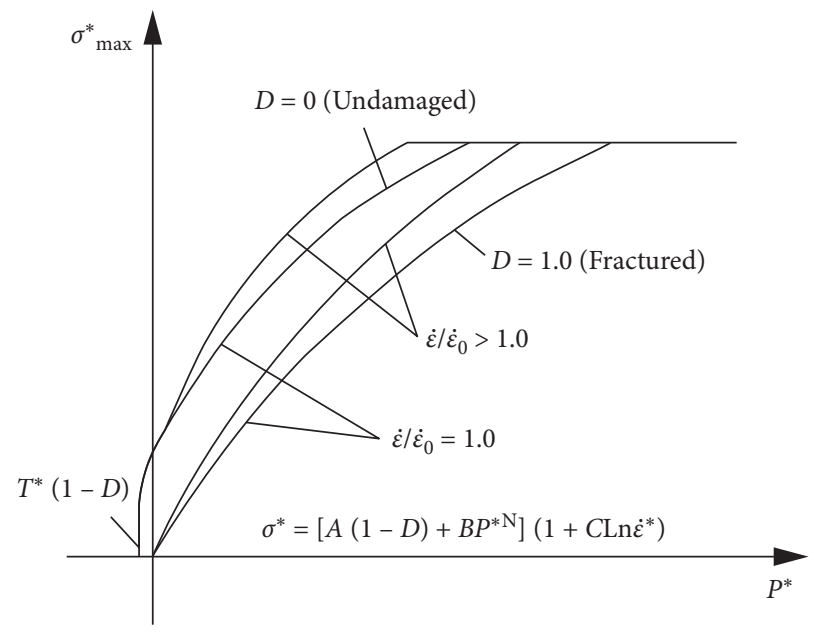

(a)

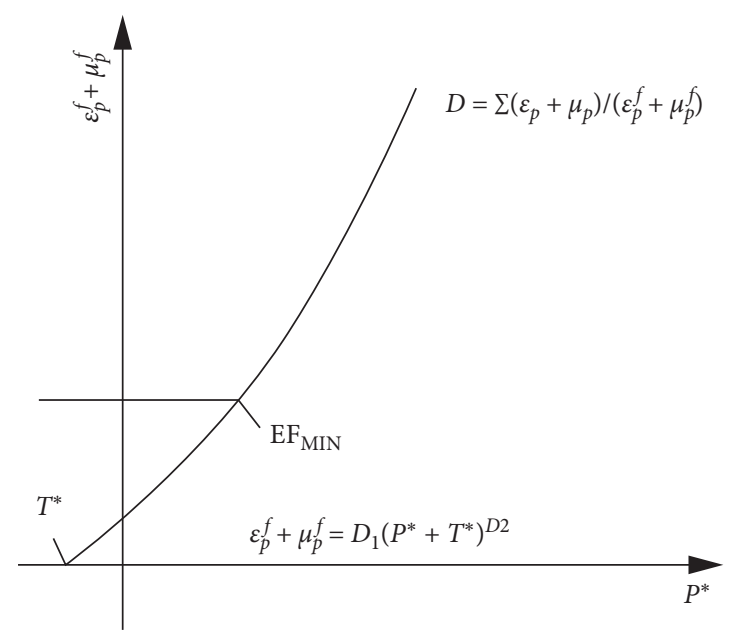

(b)

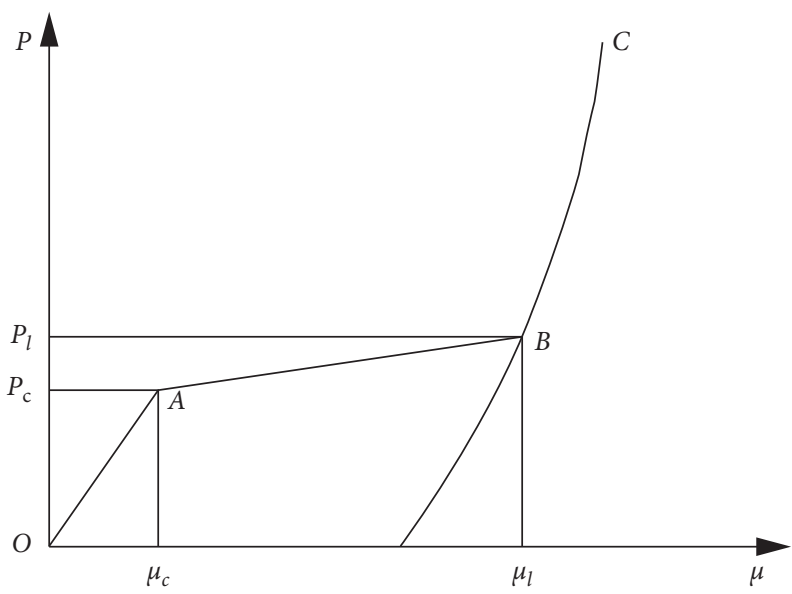

(c)

Figure 1: Original Holmquist-Johnson-Cook (HJC) model [30]. (a) Equation of the yield surface. (b) Damage model of rock and concrete. (c) Hydrostatic pressure and volumetric strain curve of rock and concrete.

Jones-Wilkins-Lee (JWL) model [33], as shown in the following equation:

$$
P=A\left(1-\frac{\omega}{R_{1} V}\right) e^{-R_{1} V}+B\left(1-\frac{\omega}{R_{2} V}\right) e^{-R_{2} V}+\frac{\omega E}{V},
$$

where $P$ is the pressure, $V$ denotes the relative volume, $E$ is the specific internal energy, and $A, B, R_{1}, R_{2}$, and $\omega$ represent the material constants, respectively.

The air radial noncoupling charging structure is predefined as the structure of the blasting hole. The null air material model and linear polynomial state equation are employed to describe the charging structure. The linear polynomial state equation for the null air material can be expressed as follows [33]:

$$
P=C_{0}+C_{1} \mu+C_{2} \mu^{2}+C_{3} \mu^{3}+\left(C_{4}+C_{5} \mu+C_{6} \mu^{2}\right) E_{0},
$$

where $C_{0}, C_{1}, C_{2}, C_{3}, \ldots, C_{6}$ represent the input coefficients of the state equation, respectively, $\mu=\left(\rho_{\text {current }} / \rho_{\text {initial }}\right)-1$ indicates the volume parameter, $\left(\rho_{\text {current }} / \rho_{\text {initial }}\right)$ is the relative density, $\rho_{\text {initial }}$ is the initial air density value, $\rho_{\text {current }}$ is the current air density, and $E_{0}$ is the initial energy density.

2.3. Failure Criterion. The rock failure under blasting loading is usually determined by the rock properties and stress state. The failure criterion of rocks depends on characteristics of the failure, crushing, and rupture zones produced after blasting. In the crushing zone, the effect of high-pressure detonation generated by blasting is remarkably more intensive than that produced by dynamic loading. In this case, the failure criterion of Mises is considered to be applicable [34]. In the rupture zone, however, the fracture network consists of vertical and annular fissures in surrounding rocks which can be attributed to the combination effects of shock wave and blasting products. Cracking in this area is assumed as tension failure, and thus, the failure criterion of rocks can be described by equations (10) and (11) $[34,35]$ : 


$$
\begin{gathered}
\left\{\begin{array}{l}
\sigma_{i}>\sigma_{y d}, \\
\sigma_{l}>\sigma_{l d},
\end{array}\right. \\
\sigma_{i}=\sqrt{\frac{\left(\sigma_{1}-\sigma_{2}\right)^{2}+\left(\sigma_{2}-\sigma_{3}\right)^{2}+\left(\sigma_{3}-\sigma_{1}\right)^{2}}{2}},
\end{gathered}
$$

where $\sigma_{i}$ is the equivalent stress, $\sigma_{l}$ represents the tensile stress, $\sigma_{y d}$ denotes the uniaxial dynamic compressive strength of the rock in the crushing zone, and $\sigma_{l d}$ indicates the uniaxial dynamic tensile strength of the rock in the rupture zone.

2.4. Erosion Algorithm. As fracturing of rocks differs from that of the joints, the erosion algorithm, which allows several fracture criteria to be predefined in the modelling, is employed to determine the fracturing processes of different materials [31]. Meanwhile, the state of rock mass in vicinity of the designed tunnel contour can also be readily understood [36]. In this investigation, the failure criterion of equivalent stress is utilized with the erosion algorithm. During numerical simulation, the element will be invalid and thus be killed by the code of LS-DYNA 3D if the calculated stress or strain state of the element meets the failure criterion predefined by the erosion algorithm.

2.5. Nonreflecting Boundaries. Reasonable boundary conditions are highly correlated with the reliability of the numerical simulation. The boundary might make the stress wave refract or reflect, resulting in unpredictable changes in the propagation of the wave [31]. To minimize such influences caused by wave reflections, the nonreflecting boundaries are utilized to simulate the infinite surrounding rock masses in the numerical modelling of tunnel smooth blasting by using LS-DYNA 3D [31, 32, 37].

2.6. Mesh Generation. In numerical investigations, the mesh size usually influences the accuracy and reliability of calculations remarkably. In this study, the number of cells is up to 16 within one load wavelength, and thus, the waveforms and peak values of all calculated physical quantities tend to be convergent. The unstructured grids are generated using HyperMesh software. The cell size depends on the element size and related density. Mesh smoothing is performed by an automesh smoothing algorithm.

2.7. Validation of the Numerical Model. Developed numerical model should be validated with a real blasting case before conducting the numerical experiments. Any inappropriate and irrational inputs must be corrected and improved firstly. Then, the refined numerical model can be utilized to perform the orthogonal experiments if the calculated results are consistent with those of the site.

2.8. Sensitivity Analysis for Factors. On the basis of results of the numerical experiments, sensitivity analysis is performed to determine the level of importance of each influential factor. The dominant factors are defined as the sensitive factors that have more significant influences on the quality of smooth blasting. According to practical experiences and previous investigations, in this work, the calculated area and distance of overbreak or underbreak are defined as the observed characteristic parameters representing the blasting quality [10]. And thus, range analysis can be used to evaluate the level of significance of each factor involved in this investigation based on the results of orthogonal experiments. The higher the value of range is (i.e., $R$ ), the greater the effect of the factor is. In the sensitivity analysis, factors involved in the numerical investigations include peripheral hole spacing $E(\mathrm{~cm})$, line of least resistance $W(\mathrm{~cm})$, charge concentration $H$ (i.e., $H=E / W)$, charging explosive $D(\mathrm{~kg} / \mathrm{m})$, type of rock mass $T$, detonation velocity $V(\mathrm{~m} / \mathrm{s})$, and drilling deviation $M$. As a result of range analysis, both dominant and secondary factors affecting greatly the quality of smooth blasting can be identified quantitatively by the value of $R$. Moreover, the optimum levels of factors for the favorable quality of smooth blasting will be achieved, and thus, the design of blasting parameters can be further improved and refined.

For an observed parameter, the value of range $R$ can be determined by equations (12)-(14):

$$
\begin{aligned}
R & =\overline{K_{j \max }}-\overline{K_{j \min }}, \\
\overline{K_{j}} & =\frac{K_{j m}}{m}, \\
K_{j m} & =\sum P_{i},
\end{aligned}
$$

where $\overline{K_{j \max }}$ and $\overline{K_{j \min }}$ are the maximum and minimum values of $\bar{K}_{j}$, respectively, $P_{i}$ is the value of the observed parameter under the effect of factor $j$ with level $m, K_{j m}$ is the sum of $P_{i}$, and $\overline{K_{j}}$ is the average value of $P_{i}$.

If the levels of factors are not identical, the value of $R$ cannot be directly utilized to determine the sensitivity. Therefore, the calculated value of $R$ should be converted to an equivalent counterpart $R /$ by equations (15) and (16):

$$
\begin{aligned}
R^{\prime} & =\mathrm{d} R \sqrt{r}, \\
r & =\frac{n}{m},
\end{aligned}
$$

in which $d$ is the coefficient associated with the levels of the factor, $n$ is the total testing time, and $m$ is the level of the factor.

\section{Case Study}

3.1. Project Background. The mountainous rock tunnel involved in this investigation is situated in Chongqing of China which served for the Chengdu-Chongqing high-speed railway. The cross section of the rock tunnel is horseshoeshaped. Excavation radius and height are $7.45 \mathrm{~m}$ and $11.08 \mathrm{~m}$, respectively. The length of the tunnel is around $5050 \mathrm{~m}$. The distance between the studied tunnel and the vicinity one is $5 \mathrm{~m}$. The lithology of surrounding rock masses 
mainly includes Jurassic sandstone, siltstone, and mudstone with highly developed fractures and joints. In this work, the surrounding rocks involved mainly consist of sandstone and silt stone which are also considered as the major waterbearing formations, and relevant properties of rocks are illustrated in Table 1. The estimated maximum water inflow is about $8000 \mathrm{~m}^{3} / \mathrm{d}$. The smooth blasting and benching tunnelling methods are employed to perform the excavation. The geological setting and site conditions of this tunnel are chosen as the inputs of the numerical investigation.

3.2. Experimental Arrangement. In this work, the factors influencing the quality of smooth blasting include perimeter hole spacing $E$, least resistance line $W$, charge concentration $H=E / W$, charging explosive $D$, type of rock mass $T$, detonation velocity $V$, and drilling deviation $M$. Four levels are assigned to the former 4 factors whereas two levels for the latter 3 factors, as shown in Table 2. It is noted that the depth of each blasting hole is $0.4 \mathrm{~m}$. The area and deviation (distance) of the actual contour after blasting are defined as observed parameters standing for the quality of smooth blasting.

As the interactions of factors are not taken into account in this study, the numerical experimental arrangement is based on orthogonal table L16 $(44 \times 23)$ with 16 investigations, as shown in Table 3. As a kind of cost-effective experimental design methods, the number of tests of orthogonal-based arrangement reduces to just $0.78 \%$ of that of the full factorial design.

3.3. Material Properties. The material parameters for the $\mathrm{HJC}$ model are determined on the basis of previous research [38-40] and site geology for the studied rock tunnel. Table 4 presents the properties of the rock masses. Table 5 shows the properties of joints.

The parameters of the rock emulsion explosive determining the model of explosive materials and the parameters for the state equation are shown in Table 6. Moreover, the properties of the null air material and inputs for the state equation are shown in Table 7 . It is noted that some of the parameters are obtained from literature studies [33, 41-44].

3.4. Numerical Modelling. The dimensions of the numerical model in $X, Y$, and $Z$ directions are $104.30 \mathrm{~m}, 100.48 \mathrm{~m}$, and $89.44 \mathrm{~m}$, respectively, as shown in Figure 2. There are a total of 4,253,586 hexahedron elements in the mesh, with three different sizes. In order to minimize the effect of mesh size on the computation results, the smallest size elements (side length $=10 \mathrm{~cm}$ ) are used in the region near the charge hole, and medium size elements (side length $=15 \mathrm{~cm}$ ) are utilized near the designed tunnel contour, while the largest elements ( side length $=60.16 \mathrm{~cm}$ ) are used for the other regions. In order to reduce the influence of reflected stress wave at boundaries, the nonreflecting boundaries are applied at least $40 \mathrm{~m}$ from the outermost charge hole according to experiences from literature studies $[24,31,36,37,45,46]$. Specifically, boundaries are at the position with a distance of 3 times excavation width from the excavation contour. The boundary at the tunnel face is defined as the free boundary, and other boundaries are set as nonreflecting boundaries.

For the joints with an inclination of $0^{\circ}$, the fracture surface is symmetrically distributed on both sides [47]. Meanwhile, a plastic fracture surface that adversely affects the stability of the tunnel will be generated on the roof if the inclination is $90^{\circ}$. In this tunnel, the overbreak observed onsite is mainly located at the sidewall and roof. To accelerate numerical modelling, two joints with an aperture of $3 \mathrm{~cm}$ are predefined at the sidewall and roof, as shown in Figure 3. The intersection angles between the joint and blast hole are $0^{\circ}$ and $90^{\circ}$, respectively. The center of the bottom of the explosive is defined as the initiation point for the slight sectional tolerance explosion. The time difference of each blast hole is $100 \mu \mathrm{s}$, while for holes at the bottom, the difference is $0 \mu \mathrm{s}$, and for periphery holes, it is $100 \mu \mathrm{s}$. The total computation time is $800 \mu \mathrm{s}$.

The process of formation of smooth blasting is shown in Figure 4 . With the initiation of detonation, the shock wave and gas with high temperature and pressure which increase rapidly with the time act on the rocks in vicinity of the blasting holes, as shown in Figure 4(a). When time is $33 \mu \mathrm{s}$, the rocks begin to crack due to intensive effect of pressing caused by blasting, and the maximum equivalent stress of the rock is about $68.38 \mathrm{MPa}$. With the propagation of shock wave and the expansion of the gas under high temperature and high pressure, the maximum equivalent stress that reaches around 1,000 $\mathrm{MPa}-10,000 \mathrm{MPa}$ becomes considerably higher than the dynamic compressive strength of the surrounding rocks. As a result, the movement of the surrounding rocks is close to the flow state, and crushing failure occurs in the surrounding rocks near the cut and pilot holes. Furthermore, the compressive stress wave propagates along the vertical direction of the hole, and thus, the interlaced vertical and annular fissure networks are formed in the rupture zone due to the interactions of the shock wave and blasting products. This occurs before the commencement of blasting in the periphery holes. Subsequently, blasting in periphery holes starts, and the surrounding rocks begin to break down. Meanwhile, the detonation produced in the periphery hole causes a strong stress wave. The range of the rock damage is further increased at the time of $146 \mu \mathrm{s}$, as shown in Figure 4(b). When time is $217 \mu$ s (see Figure 4(c)), the wave interference occurs due to the stress waves produced from the adjacent holes. This leads to a tensile stress concentration generated in the area between adjacent holes and thus promotes the formation of penetrating cracks. In this case, the maximum equivalent stress of the rock unit is about 177.6 $\mathrm{MPa}$, and the tunnel blasting contour is formed accordingly. However, the blasting energy is not completely exhausted, and thus, it drives the stress wave to propagate forward. This results in growth of volume of the overexcavated zone, as shown in Figures 4(d) and 4(e). Meanwhile, the maximum equivalent stress of the rock unit decreases from 103.6 MPa to 73.8 MPa. Thereafter, with the gradually exhausted energy, the maximum stress will be lower than the dynamic compressive strength of the surrounding rock, and as a result, it cannot cause further cracking and crushing failure. At the time of $608 \mu \mathrm{s}$, the 
Table 1: Properties of the rock mass.

Physical-mechanical parameters of the rock mass

\begin{tabular}{cccccccc}
\hline \multirow{2}{*}{ Level } & \multicolumn{7}{c}{ Physical-mechanical parameters of the rock mass } \\
& Type & Density $\left(\mathrm{g} / \mathrm{cm}^{3}\right)$ & Internal friction angle $\left(^{\circ}\right)$ & Cohesion $(\mathrm{MPa})$ & Elastic modulus $(\mathrm{GPa})$ & Poisson's ratio & Joint (set) \\
\hline 1 & III & 2.45 & 33 & 0.6 & 10 & 0.28 & 0 \\
2 & IV & 2.15 & 15 & 0.05 & 1.2 & 0.4 & 2 \\
\hline
\end{tabular}

TABLE 2: Factors and levels for the orthogonal design.

\begin{tabular}{|c|c|c|c|c|c|c|c|}
\hline \multirow[b]{2}{*}{ Level } & \multicolumn{7}{|c|}{ Factors } \\
\hline & $\begin{array}{l}\text { Perimeter hole } \\
\text { spacing } E(\mathrm{~cm})\end{array}$ & $\begin{array}{l}\text { Least resistance } \\
\text { line } W(\mathrm{~cm})\end{array}$ & $\begin{array}{c}\text { Charge } \\
\text { concentration } \\
H=E / W\end{array}$ & $\begin{array}{l}\text { Charging } \\
\text { explosive } \\
D(\mathrm{~kg} / \mathrm{m})\end{array}$ & $\begin{array}{c}\text { Type of rock } \\
\text { mass } T\end{array}$ & $\begin{array}{c}\text { Detonation velocity } \\
\qquad V(\mathrm{~m} / \mathrm{s})\end{array}$ & $\begin{array}{c}\text { Drilling } \\
\text { deviation } M\end{array}$ \\
\hline 1 & 50 & 55 & 0.93 & 0.15 & III & 3200 & Qualified (1) \\
\hline 2 & 60 & 60 & 1 & 0.25 & IV & 5200 & Poor (2) \\
\hline 3 & 70 & 65 & 1.07 & 0.35 & - & - & - \\
\hline 4 & 80 & 70 & 1.14 & 0.45 & - & - & - \\
\hline
\end{tabular}

TABLE 3: Orthogonal test design of tunnel blasting quality.

\begin{tabular}{|c|c|c|c|c|c|c|c|}
\hline \multirow[b]{2}{*}{ Test no. } & \multicolumn{7}{|c|}{ Factors } \\
\hline & $\begin{array}{l}\text { Perimeter hole } \\
\text { spacing } E(\mathrm{~cm})\end{array}$ & $\begin{array}{l}\text { Least resistance } \\
\text { line } W(\mathrm{~cm})\end{array}$ & $\begin{array}{c}\text { Charge concentration } \\
\qquad H=E / W\end{array}$ & $\begin{array}{c}\text { Charging explosive } \\
D(\mathrm{~kg} / \mathrm{m})\end{array}$ & $\begin{array}{c}\text { Type of rock } \\
\text { mass } T\end{array}$ & $\begin{array}{c}\text { Detonation } \\
\text { velocity } \\
V(\mathrm{~m} / \mathrm{s})\end{array}$ & $\begin{array}{c}\text { Drilling } \\
\text { deviation } M\end{array}$ \\
\hline 1 & 50 & 55 & 0.93 & 0.15 & 1 & 3200 & 1 \\
\hline 2 & 50 & 60 & 1 & 0.25 & 1 & 5200 & 2 \\
\hline 3 & 50 & 65 & 1.07 & 0.35 & 2 & 3200 & 2 \\
\hline 4 & 50 & 70 & 1.14 & 0.45 & 2 & 5200 & 1 \\
\hline 5 & 60 & 55 & 1 & 0.35 & 2 & 5200 & 1 \\
\hline 6 & 60 & 60 & 0.93 & 0.45 & 2 & 3200 & 2 \\
\hline 7 & 60 & 65 & 1.14 & 0.15 & 1 & 5200 & 2 \\
\hline 8 & 60 & 70 & 1.07 & 0.25 & 1 & 3200 & 1 \\
\hline 9 & 70 & 55 & 1.07 & 0.45 & 1 & 5200 & 2 \\
\hline 10 & 70 & 60 & 1.14 & 0.35 & 1 & 3200 & 1 \\
\hline 11 & 70 & 65 & 0.93 & 0.25 & 2 & 5200 & 1 \\
\hline 12 & 70 & 70 & 1 & 0.15 & 2 & 3200 & 2 \\
\hline 13 & 80 & 55 & 1.14 & 0.25 & 2 & 3200 & 2 \\
\hline 14 & 80 & 60 & 1.07 & 0.15 & 2 & 5200 & 1 \\
\hline 15 & 80 & 65 & 1 & 0.45 & 1 & 3200 & 1 \\
\hline 16 & 80 & 70 & 0.93 & 0.35 & 1 & 5200 & 2 \\
\hline
\end{tabular}

Table 4: Properties of rock masses for the HJC model.

\begin{tabular}{|c|c|c|c|c|c|c|}
\hline Density $\left(\mathrm{g} / \mathrm{cm}^{3}\right)$ & Cohesion (MPa) & Elasticity modulus (GPa) & Poisson's ratio & $A$ & $B$ & C \\
\hline $2.45 / 2.15$ & $0.6 / 0.05$ & $10 / 1.2$ & $0.28 / 0.4$ & 0.79 & 1.6 & 0.007 \\
\hline D1 & D2 & $\mathrm{N}$ & $\mathrm{T}$ & K1 & $\mathrm{K} 2$ & K3 \\
\hline 0.04 & 1.00 & 0.61 & $3.15 \mathrm{E}-05$ & 0.174 & 0.388 & 0.298 \\
\hline
\end{tabular}

Table 5: Properties of joints for the bilinear kinematic model.

\begin{tabular}{lccccc}
\hline $\begin{array}{l}\text { Density } \\
\left(\mathrm{g} / \mathrm{cm}^{3}\right)\end{array}$ & $\begin{array}{c}\text { Elastic modulus } \\
(105 \mathrm{MPa})\end{array}$ & Poisson's ratio & $\begin{array}{c}\text { Compressive } \\
\text { strength }(105 \mathrm{MPa})\end{array}$ & $\begin{array}{c}\text { Shear strength } \\
(105 \mathrm{MPa})\end{array}$ & $\begin{array}{c}\text { Hardening } \\
\text { parameter }\end{array}$ \\
\hline 2.4 & 0.45 & 0.27 & $6.00 \mathrm{E}-03$ & 0.177 \\
\hline
\end{tabular}

TABLe 6: Parameters used for the high-performance explosive material model.

\begin{tabular}{lcccccccc}
\hline Density $\left(\mathrm{g} / \mathrm{cm}^{3}\right)$ & Detonation velocity $(\mathrm{cm} / \mu \mathrm{s})$ & $\mathrm{CJ}$ pressure $(105 \mathrm{MPa})$ & $A(\times 105 \mathrm{MPa})$ & $B(\times 105 \mathrm{MPa})$ & $R_{1}$ & $R_{2}$ & $\mathrm{Omeg}$ & $E 0(\times 105 \mathrm{MPa})$ \\
\hline 1.3 & 0.4 & 0.106 & 2.144 & 0.00182 & 4.2 & 0.9 & 0.15 & 0.04192 \\
\hline
\end{tabular}


TABLE 7: Parameters used for the null air material model.

\begin{tabular}{lcccccccc}
\hline Density $\left(\mathrm{g} / \mathrm{cm}^{3}\right)$ & $C 0$ & $C 1$ & $C 2$ & $C 3$ & $C 4$ & $C 5$ & $C 6$ & $E 0(\times 105 \mathrm{MPa})$ \\
\hline $1.54 E-03$ & 0 & 0 & 0 & 0 & 0.4 & 0.4 & 0 & $2.50 E-06$ \\
\hline
\end{tabular}

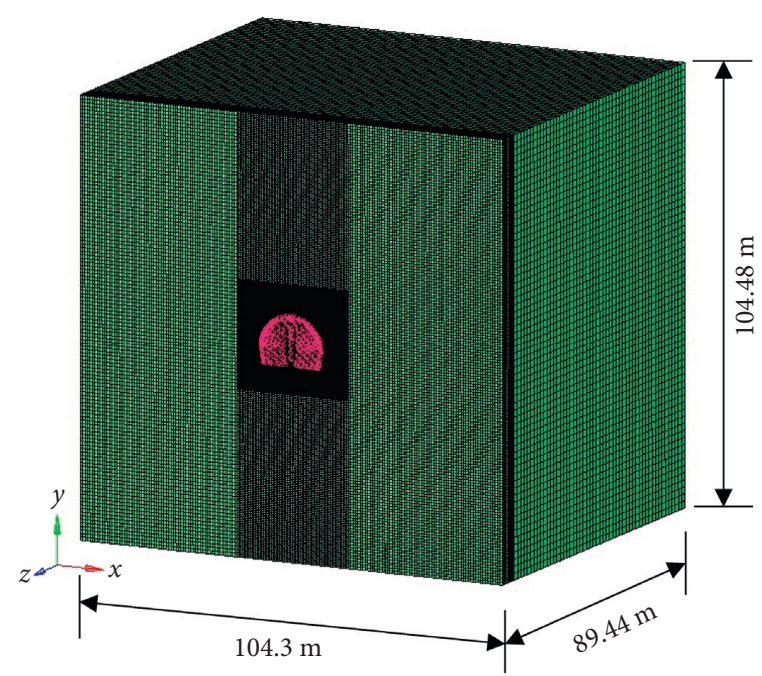

(a)

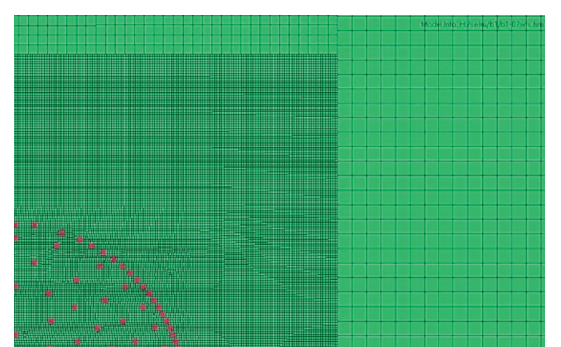

(b)

Figure 2: The 3D numerical model for tunnel smooth blasting. (a) The calculation domain. (b) Three types of elements.

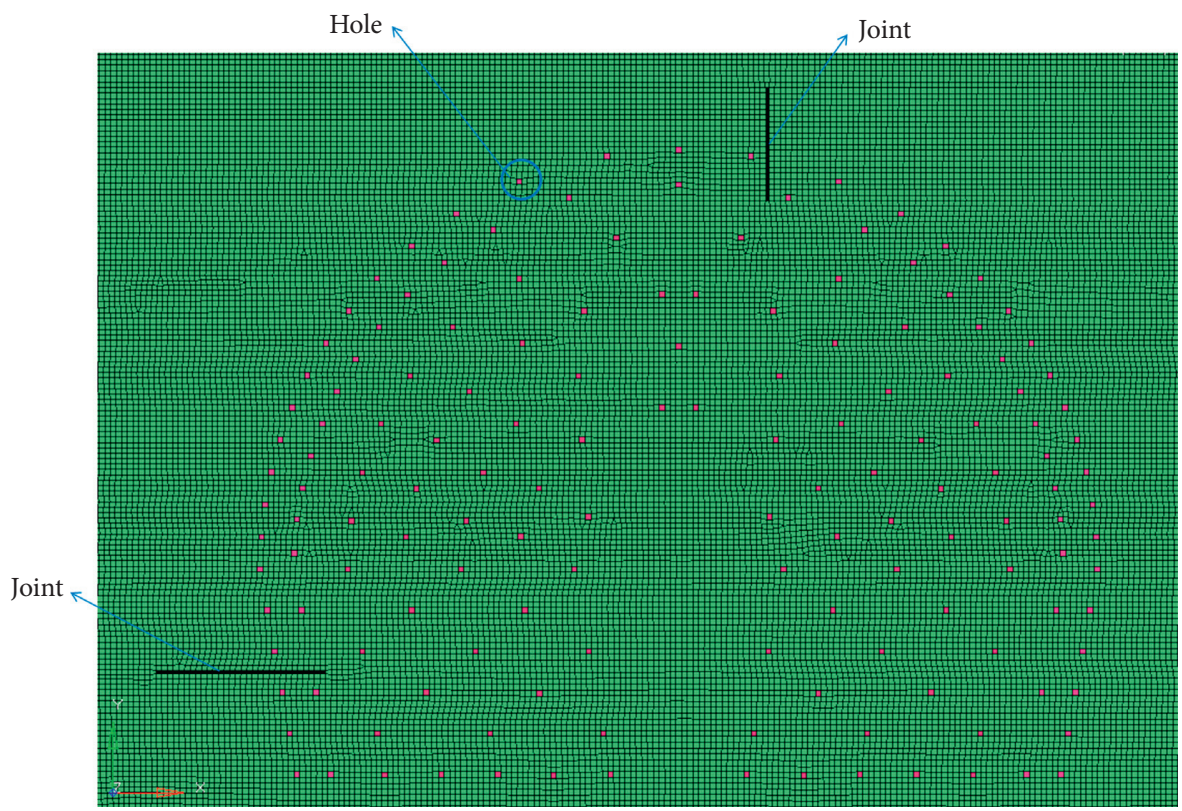

FIgURE 3: Schematic of the joints.

maximum equivalent stress of the rock unit is $43.39 \mathrm{MPa}$. At the end of the calculation (i.e., $809 \mu$ s), Figures 4(f) and 4(g) show the final tunnel contour after blasting, and the maximum equivalent stress of the rock is $51.23 \mathrm{MPa}$.

In general, the geometry of the tunnel sidewall and roof after blasting is in line with expectations. Although the tunnel contour has a continuous even surface, most overbreaks do exist at the sidewall and roof, whereas the underbreaks commonly occur at the bottom. The developed model has been validated by a real blasting case in this tunnel to improve the accuracy of the investigation. The actual contour of the real blasting case conducted on-site was measured using a tunnel profilometer. By comparing the measured data with the calculated results from numerical modelling, both positions and dimensions of the over-/underbreaks obtained on-site were consistent well with the numerical modelling results, as shown in Figure 5. It is believed that the developed numerical model is applicable and reliable to investigate smooth blasting. 


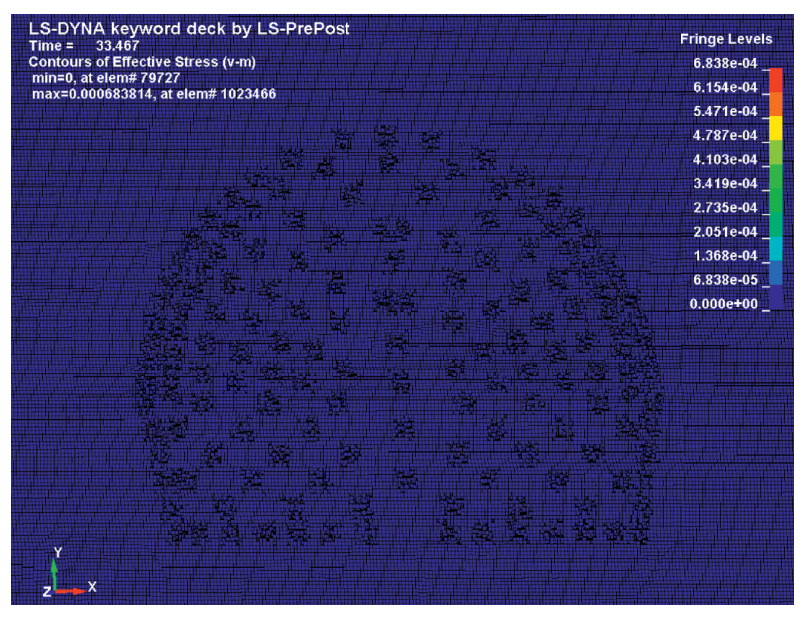

(a)

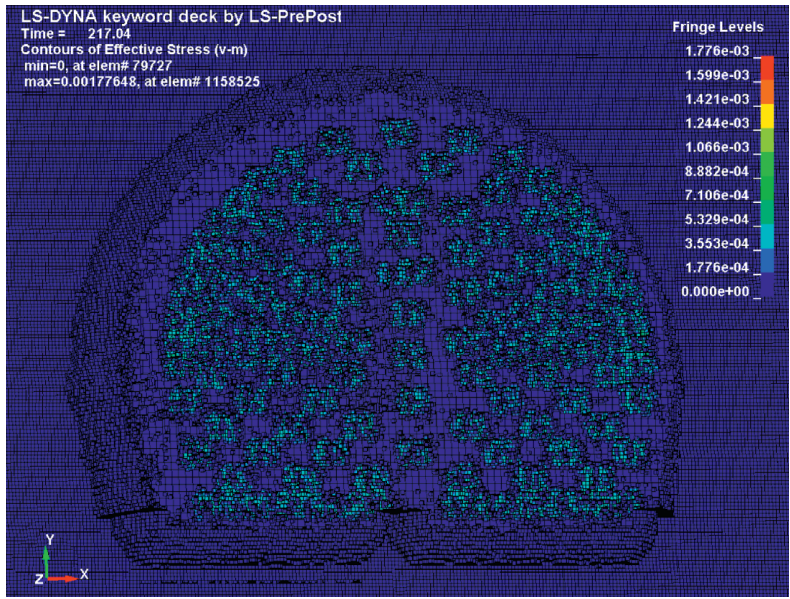

(c)

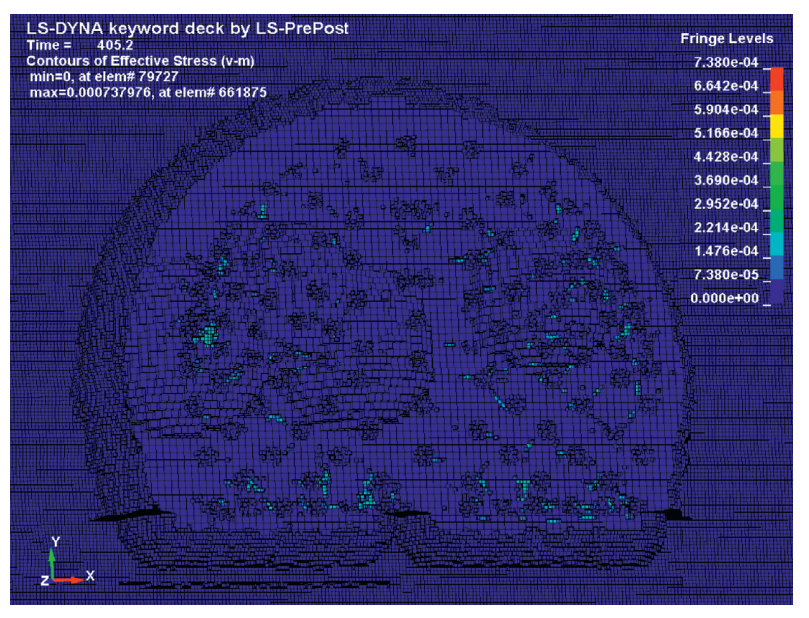

(e)

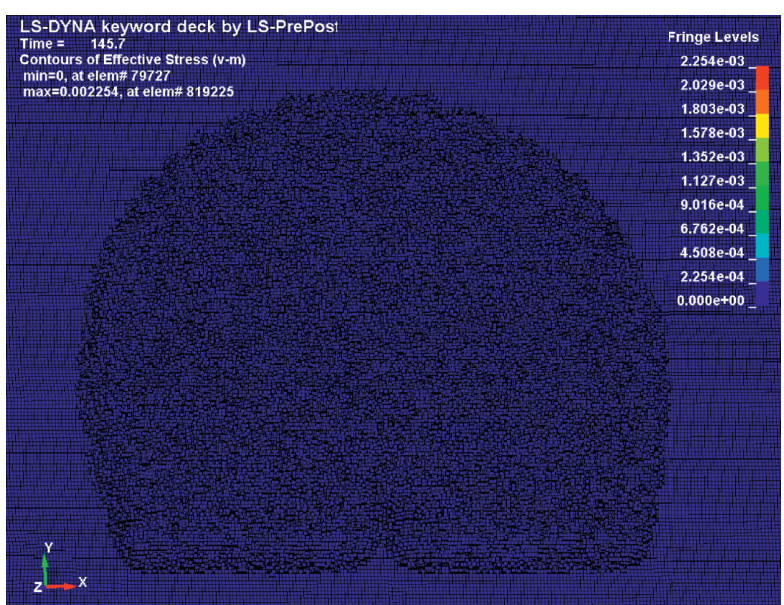

(b)

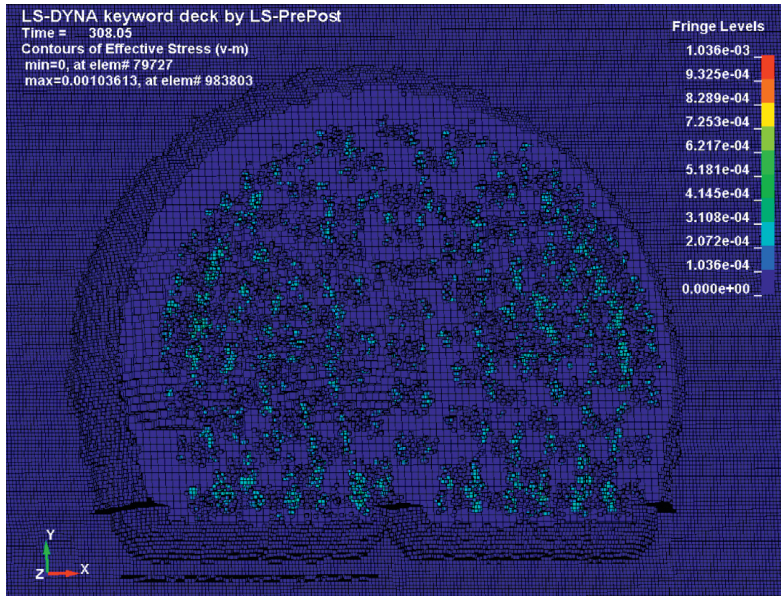

(d)

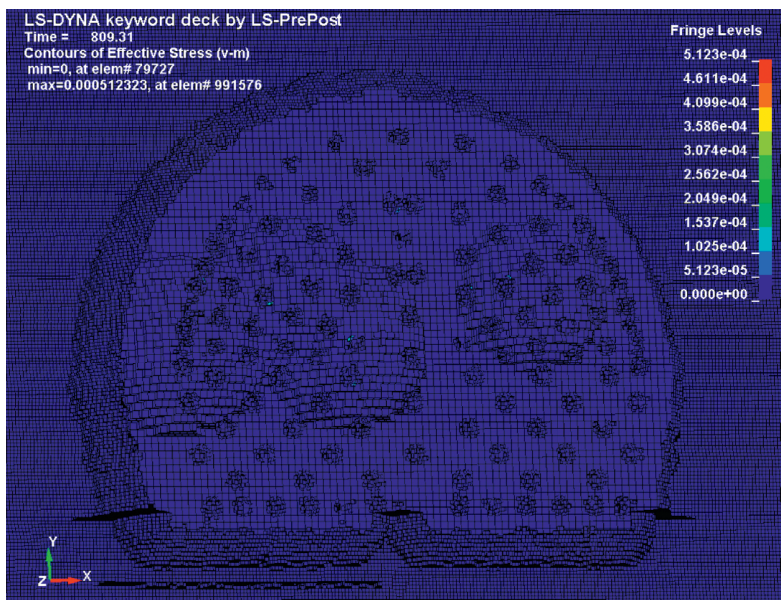

(f)

Figure 4: Continued. 


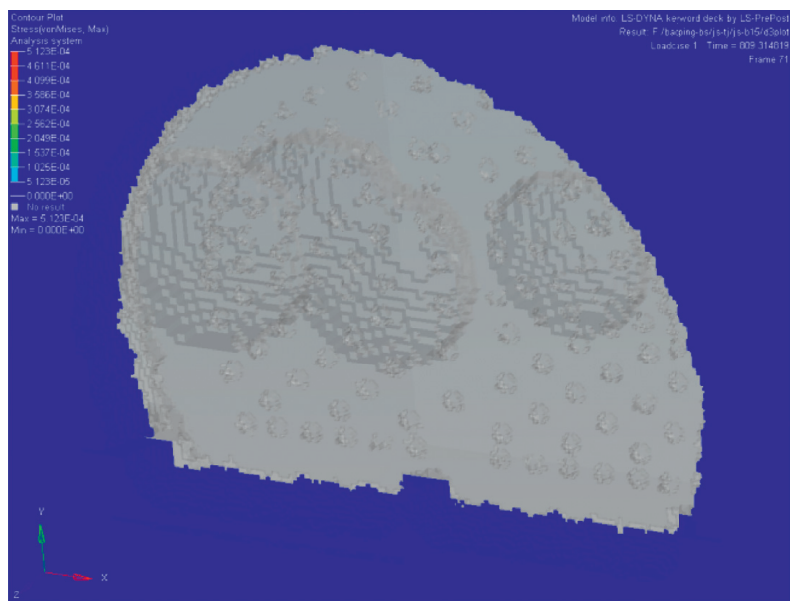

(g)

Figure 4: Process of smooth blasting. (a) $33 \mu \mathrm{s}$. (b) $146 \mu \mathrm{s}$. (c) $217 \mu \mathrm{s}$. (d) $308 \mu \mathrm{s}$. (e) $405 \mu \mathrm{s}$. (f) $809 \mu \mathrm{s}$. (g) The final contour.

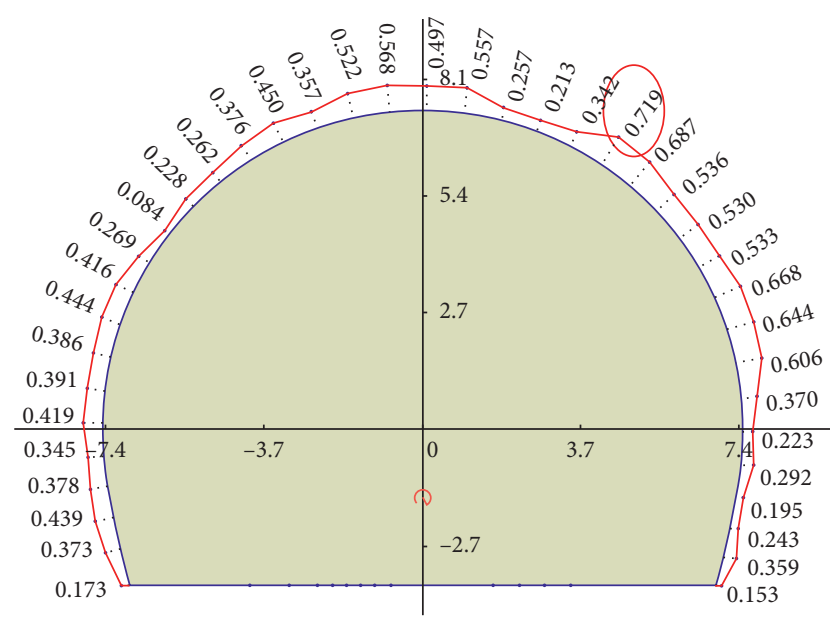

FIGURE 5: Validation of numerical modelling with the site data.

Thereafter, the numerical experiments based on the predetermined orthogonal arrangement were conducted successively to investigate the influential factors.

\section{Results and Discussion}

4.1. Calculated Parameters Representing the Blasting Quality. The actual dimensions of the cross section after blasting were calculated to quantitatively determine the quality of smooth blasting in this investigation. The cross section with a distance of $1.8 \mathrm{~m}$ from the initial tunnel face before blasting is selected to estimate the blasting quality characterized by area and the maximum value of distance of the over-/underbreak. For quantitative evaluation of the aforementioned parameters associated with the quality of smooth blasting, the area of the designed cross section is predefined at $145.1 \mathrm{~m}^{2}$, considering the acceptable deformation of the surrounding rock mass which is predefined as $20 \mathrm{~cm}$. Then, the coordinates of the actual contour after blasting can be obtained from the numerical model and thus be compared with those of the designed contour, as shown in Figure 6. Consequently, the actual area and maximum

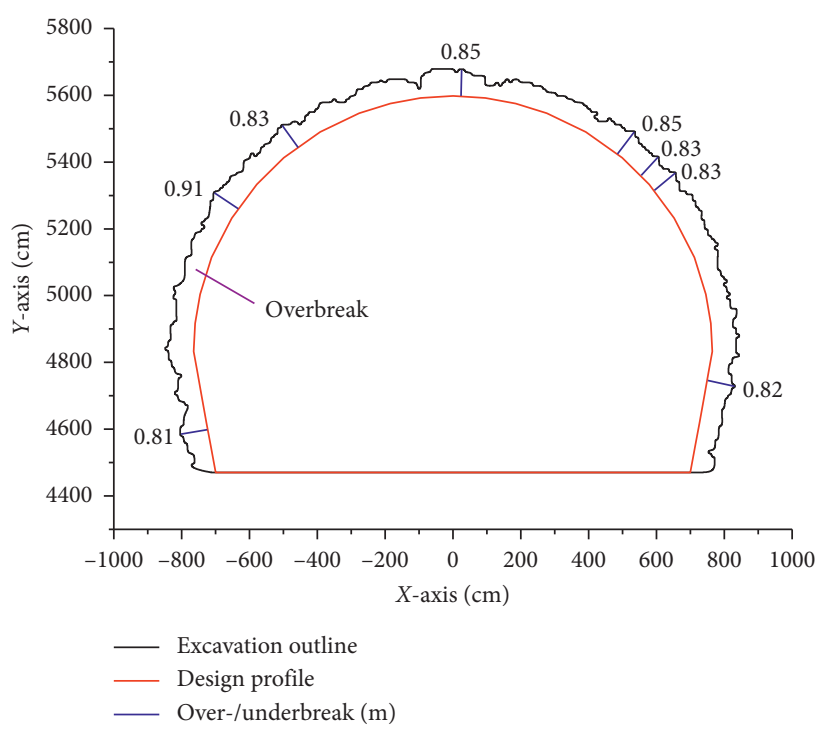

FIgURE 6: The actual tunnel contour after blasting (based on the 15th test in the orthogonal table).

distance of over-/underbreak can be quantitatively calculated. Based on the orthogonal arrangement, the computed results for the 16 tests are shown in Table 8.

For the area of the cross section after blasting under influential factors with various levels, it can be seen that the maximum value is up to $167.48 \mathrm{~m}^{2}$, which occurs under the conditions of the 10th test, whereas the minimum value is $145 \mathrm{~m}^{2}$ that is observed under the conditions of the 6th test, as shown in Figure 7. Regarding the area of overbreak, the maximum value reaches $22.38 \mathrm{~m}^{2}$, which is also observed under the conditions of the 10th test, while the minimum overbreak area is $2.61 \mathrm{~m}^{2}$, which still occurs under the conditions of the 6th test. Meanwhile, for the area of underbreak, the maximum value is $2.74 \mathrm{~m}^{2}$ that occurs under the conditions of the 6th test. However, there is no underbreak observed in 10th and 15th tests. 
TABLE 8: Calculated results.

\begin{tabular}{lcccc}
\hline $\begin{array}{l}\text { Test } \\
\text { no. }\end{array}$ & $\begin{array}{c}\text { Cross-section } \\
\text { area }\left(\mathrm{m}^{2}\right)\end{array}$ & $\begin{array}{c}\text { Underbreak } \\
\text { area }\left(\mathrm{m}^{2}\right)\end{array}$ & $\begin{array}{c}\text { Overbreak } \\
\text { area }\left(\mathrm{m}^{2}\right)\end{array}$ & $\begin{array}{c}\text { Maximum } \\
\text { distance of } \\
\text { overbreak }(\mathrm{m})\end{array}$ \\
\hline 1 & 154.29 & 0.78 & 9.97 & 1.1 \\
2 \\
2
\end{tabular}

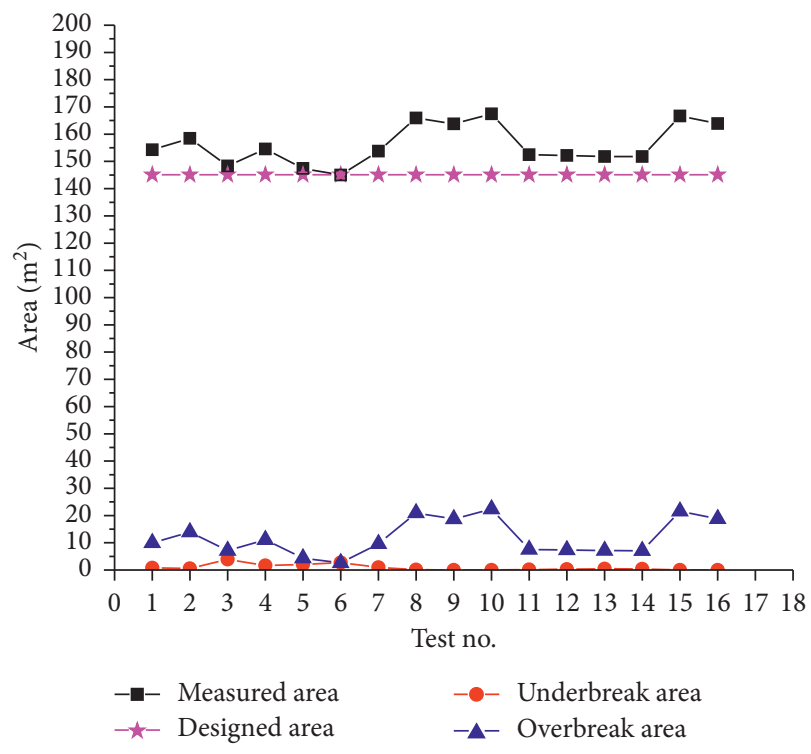

FIGURE 7: Calculated areas of the cross section and over-/ underbreak.

Deviations of the actual contours can also be estimated by comparative calculation. For each test, the maximum value of the deviations of over-/underbreak on different points of the actual contour was defined as the distance of over-underbreaks under corresponding test conditions. For the distance of overbreak, the maximum and minimum values of $1.18 \mathrm{~m}$ and $0.42 \mathrm{~m}$ are found in the $3 \mathrm{rd}$ test and $5 \mathrm{th}$ test, respectively, as illustrated in Figure 8. Regarding the deviation of underbreak, the maximum distance is $0.56 \mathrm{~m}$ in the 3rd test. There is no underbreak observed under the conditions of 10th and 15th tests. In general, the calculated results are consistent well with the site under different testing conditions. It also confirmed the reliability of replacement of the costly and time-consuming field tests or laboratory experiments by numerical modelling to investigate smooth blasting. The calculated results will be utilized to

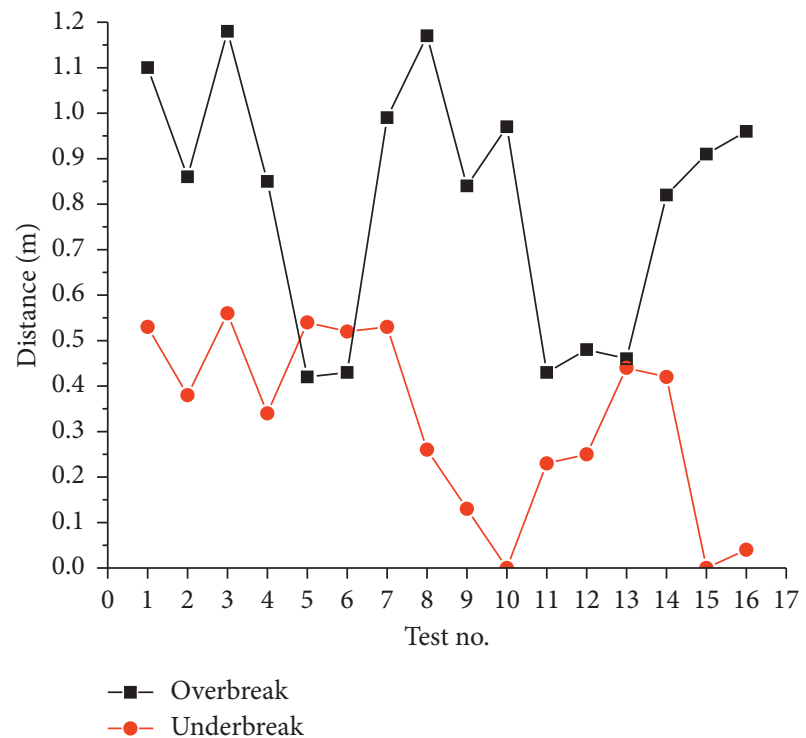

Figure 8: Calculated distance of over-/underbreak.

quantitatively evaluate the level of importance of each influential factor.

4.2. Sensitivity Analysis. The dominant factors usually determine the advancement rate and development of things. Whether a factor becomes a dominant factor depends on its effect level on the thing. The level of importance of each factor affecting the quality of smooth blasting relies on the properties of the factor and its level. Quantitative determination of the effect of every factor is more reliable and applicable than the conventional qualitative estimations. On the basis of results obtained via numerical investigation, the sensitivity of each influential factor can be determined by range analysis derived from the orthogonal experiments. In this work, the area and distance of over-/underbreak are predefined as the observed parameters that represent the quality of smooth blasting. The sensitivities of the factors 
TABLE 9: Range analysis for the overbreak area.

\begin{tabular}{lcccccc}
\hline Factor & $E$ & $W$ & $H$ & $D$ & $T$ & $V$ \\
$\overline{K_{1 j}}$ & 10.52 & 10.04 & 9.72 & 8.50 & 16.99 & 12.39 \\
$\overline{K_{2 j}}$ & 9.38 & 11.49 & 11.80 & 12.38 & 6.78 & 11.38 \\
$\overline{K_{3 j}}$ & 13.99 & 11.46 & 13.46 & 13.16 & & 10.66 \\
$\overline{K_{4 j}}$ & 13.65 & 14.55 & 12.56 & 13.50 & & \\
$R_{j}$ & 4.61 & 4.50 & 3.74 & 5.00 & 10.22 & 1.01 \\
$R_{j}^{\prime}$ & 4.149 & 4.05 & 3.366 & 4.5 & 20.524 & 2.028 \\
\hline
\end{tabular}

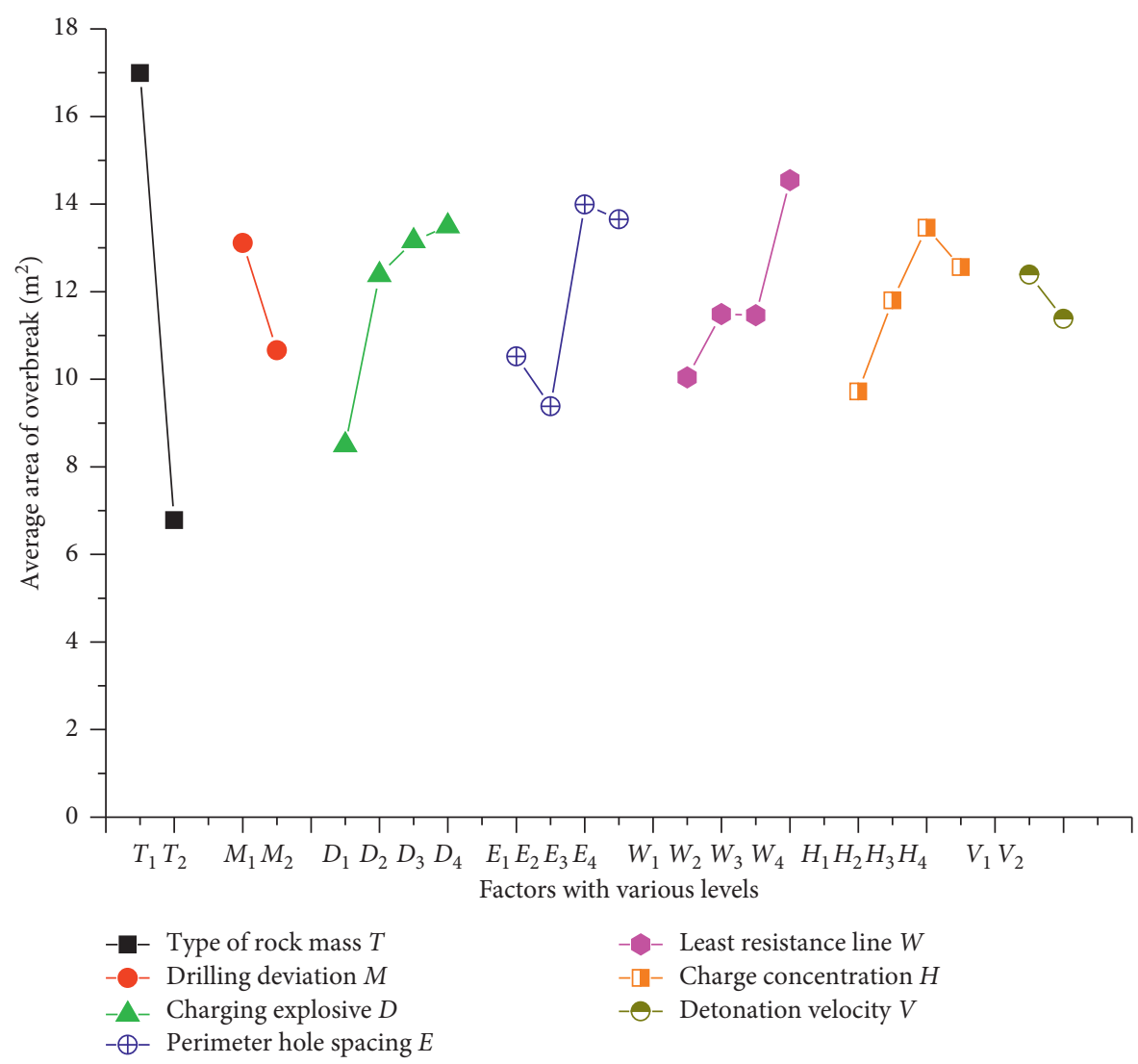

FIGURE 9: Overbreak area under various levels.

including peripheral hole spacing $E(\mathrm{~cm})$, line of least resistance $W(\mathrm{~cm})$, charge concentration $H(E / W)$, charging explosive $D(\mathrm{~kg} / \mathrm{m})$, type of rock mass $T$, detonation velocity $V(\mathrm{~m} / \mathrm{s})$, and drilling deviation $M$ to the area and distance of over-/underbreak are indicated by the value of range. The optimal level of each factor can be determined by the average value of the predefined observed parameters.

Regarding the area of overbreak, the results of range analysis are given in Table 9. According to the values of $R_{j}^{\prime}$, it can be seen that the most important factor that most considerably affect the area of overbreak is the type of rock mass $T$, and other influential factors can be determined in the descending order as follows: drilling deviation $M$, charging explosive $D$, peripheral hole spacing $E$, line of least resistance $W$, charge concentration $H(E / W)$, and detonation velocity $V$. The variation of overbreak area vs. different factorial levels is shown in Figure 9. As the lower value of the overbreak area usually means a favorable quality of blasting, it can be found that the more fractured rock might produce much larger overbreak than that of the less fractured rock mass, while the greater distance between blasting holes and line of least resistance also results in larger overbreak. Furthermore, the lower the charging explosive is, the smaller the overbreak will be.

For the area of underbreak, the results of range analysis are shown in Table 10. It can be seen that the type of rock mass and peripheral hole spacing have greatest effects on the underbreak area, which can be considered as the dominant factors. The change explosive, drilling deviation, line of least resistance, and detonation velocity are considered as the secondary influential factors. The evolution of the area of underbreak under factors with various levels is illustrated in Figure 10. Similar to the overbreak, low area of underbreak always means a desirable blasting quality. Therefore, the 
TABLE 10: Range analysis for the underbreak area.

\begin{tabular}{|c|c|c|c|c|c|c|c|}
\hline Factor & $E$ & $W$ & $H$ & $D$ & $T$ & $V$ & $M$ \\
\hline$\overline{\overline{K_{1 j}}}$ & 1.72 & 0.82 & 0.91 & 0.60 & 0.30 & 1.03 & 0.64 \\
\hline$\overline{K_{2 j}}$ & 1.45 & 0.92 & 0.72 & 0.32 & 1.44 & 0.72 & 1.11 \\
\hline$\overline{K_{3 j}}$ & 0.11 & 1.25 & 1.11 & 1.49 & & & \\
\hline$\overline{K_{4 j}}$ & 0.21 & 0.51 & 0.75 & 1.09 & & & \\
\hline$R_{j}$ & 1.61 & 0.74 & 0.39 & 1.17 & 1.14 & 0.31 & 0.47 \\
\hline$R_{j}^{\prime}$ & 1.449 & 0.666 & 0.351 & 1.053 & 2.289 & 0.623 & 0.944 \\
\hline
\end{tabular}

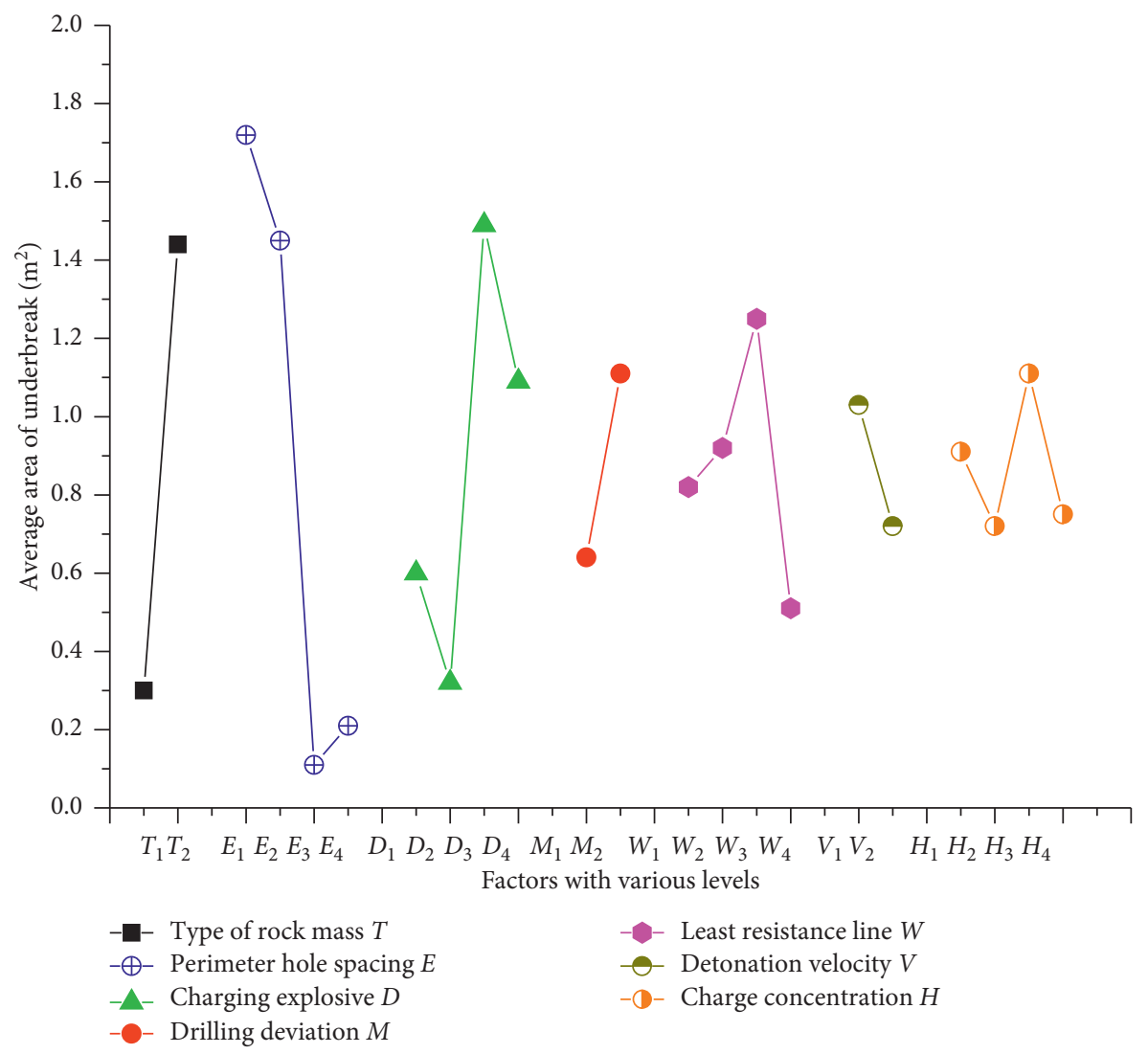

FIGURE 10: Underbreak area under various levels.

TABLE 11: Range analysis for the distance of overbreak.

\begin{tabular}{lccccccc}
\hline Factor & $E$ & $W$ & $H$ & $D$ & $T$ & \multicolumn{1}{c}{ T } \\
$\overline{\overline{K_{1 j}}}$ & 0.998 & 0.705 & 0.730 & 0.848 & 0.975 & 0.838 \\
$\overline{K_{2 j}}$ & 0.753 & 0.770 & 0.668 & 0.730 & 0.634 & 0.771 \\
$\overline{K_{3 j}}$ & 0.680 & 0.878 & 1.003 & 0.883 & & 0.775 \\
$\overline{K_{4 j}}$ & 0.788 & 0.865 & 0.818 & 0.758 & & \\
$R_{j}$ & 0.318 & 0.173 & 0.335 & 0.153 & 0.341 & 0.066 \\
$R_{j}^{\prime}$ & 0.286 & 0.156 & 0.302 & 0.138 & 0.685 & 0.133 \\
\hline
\end{tabular}

TABLE 12: Range analysis for the distance of underbreak.

\begin{tabular}{lcccccr}
\hline Factor & $E$ & $W$ & $H$ & $D$ & $T$ & \multicolumn{1}{c}{ T } \\
\hline$\overline{K_{1 j}}$ & 0.453 & 0.410 & 0.330 & 0.433 & 0.234 & 0.320 \\
$\overline{K_{2 j}}$ & 0.463 & 0.330 & 0.293 & 0.328 & 0.413 & 0.326 \\
$\overline{K_{3 j}}$ & 0.153 & 0.330 & 0.343 & 0.285 & & 0.356 \\
$\overline{K_{4 j}}$ & 0.225 & 0.223 & 0.328 & 0.248 & & \\
$R_{j}^{\prime}$ & 0.238 & 0.188 & 0.050 & 0.185 & 0.179 & 0.006 \\
$R_{j}^{\prime}$ & 0.214 & 0.169 & 0.045 & 0.167 & 0.359 & 0.012 \\
\hline
\end{tabular}




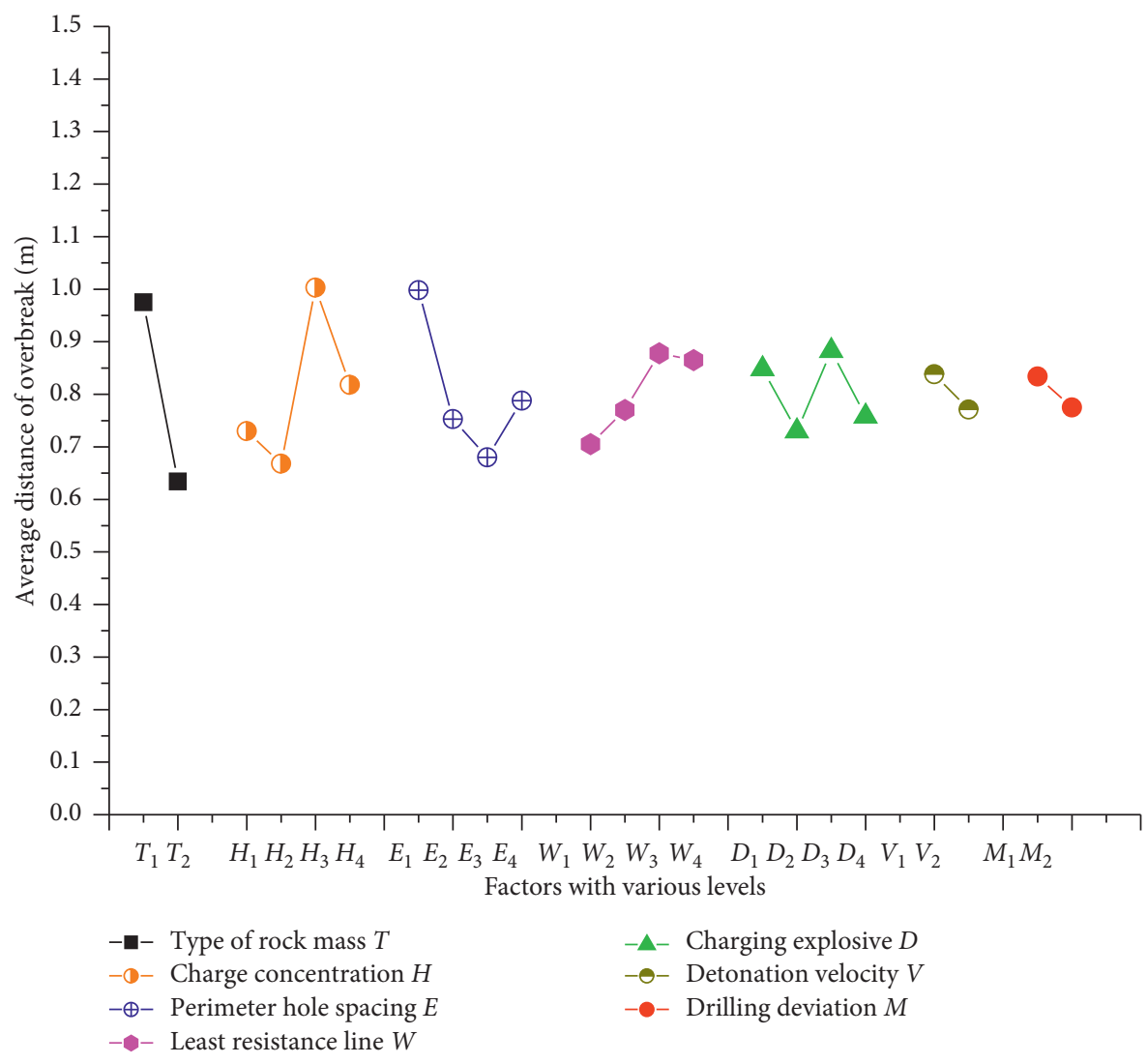

FIGURE 11: Distance of overbreak under various levels.

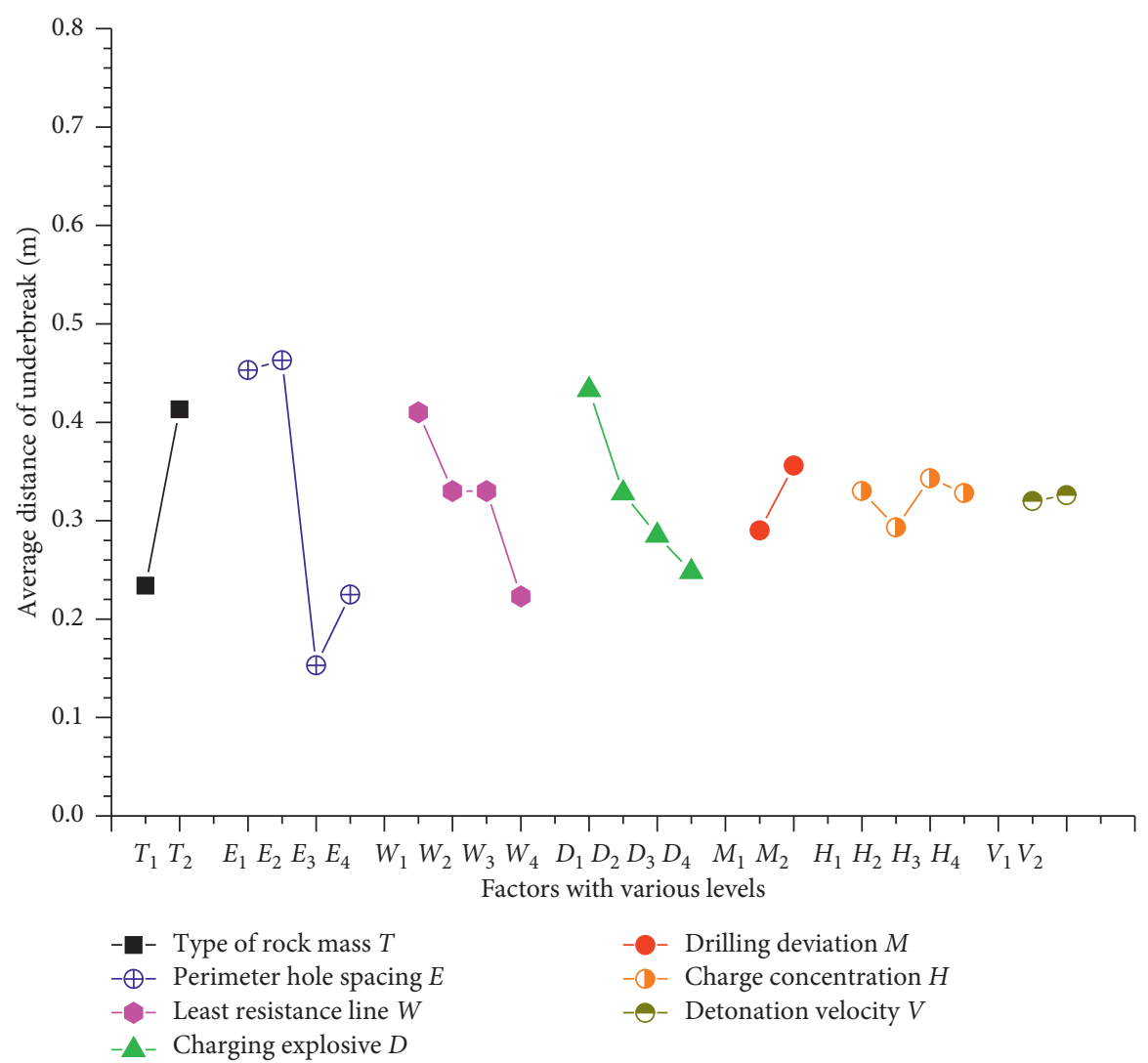

FIGURE 12: Distance of underbreak under various levels. 
perimeter hole spacing of $70 \mathrm{~cm}$, the least resistance line of $70 \mathrm{~cm}$, and changing explosive of $0.25 \mathrm{~kg} / \mathrm{m}$ will lead to a minimum underbreak area.

Regarding the distances of over-/underbreak, the range analysis results are given in Tables 11 and 12, respectively. It can be found that the type of rock mass has the most significant effect on both distances of both over- and underbreak. For the distance of overbreak, factors including line of least resistance, charging explosive, and detonation velocity, as well as drilling deviation, can be considered as secondary factors, and their influences on the overbreak can be neglected to some extent, as shown in Figure 11. On the contrary, the factors including the detonation velocity and charge concentration have little effects on the distance of underbreak, as shown in Figure 12.

In general, the numerical investigation indicated that overbreak caused by smooth blasting is much greater than underbreak. In view of this, the overbreak caused by blasting should be paid special attention in practical applications owing to it correlates closely to the cost and safety of tunnelling. Based on the sensitivity results, the type of rock mass has the greatest influence on both overbreak and underbreak. This reminds us that the properties of surrounding rock masses should be focused firstly. Accordingly, the determination of parameters of smooth blasting considerably depends on the rock masses. For estimation of both overbreak and underbreak, the effects caused by the charging concentration and detonation velocity are very limited. If the area/volume of overbreak is defined as the observed parameter representing the blasting quality, the dominant factors can be determined in the descending order as the type of rock mass, drilling deviation, charge explosive, perimeter hole spacing, and least resistance line. In blasting design, values of dominant factors should be close to their optimal levels. The charge concentration and detonation velocity, however, can be considered as the secondary parameters for smooth blasting. The values of secondary factors could be flexibly defined in consideration of both cost and construction rate.

\section{Conclusions}

In order to quantitatively understand the effects of influential factors that affect the quality of smooth blasting, specifically the damage of the surrounding rock mass, a numerical investigation is conducted in this work. Instead of costly and time-consuming field/laboratory physical tests, the arrangement of numerical experiments performed by LS-DYNA 3D is optimized by the orthogonal design to improve the efficiency of the numerical investigation. Considering the fracturing of rocks differs from that of the joints, the effect of pre-existing fractures and joints on rock responses under blasting should be paid special attentions. Moreover, the influences of brittle nature of rock materials on the dynamic behavior of rocks should be emphasized in determination of values of parameters of the HJC model. The range analysis is employed to determine the sensitivity of the factors involved. The area and distance of overbreak are defined as the indicators that represent the quality of smooth blasting. Results indicate that the shape of the tunnel contour is of regularity, and under-/overbreak is inevitably caused. Under the same conditions, the magnitude of overbreak is much greater than that of underbreak. This is consistent with the conservative design concept of practical applications. The type of rock mass, as the most important factor, greatly influences both overbreak and underbreak, and thus, it deserves the most attention to be paid in the blasting design. On the other hand, it is found that charge concentration and detonation velocity have little effect on the overbreak, which can be considered as the secondary factors for smooth blasting. For the improvement of parameter design of smooth blasting, therefore, the values of dominant factors including the type of rock mass, drilling deviation, charge explosive, perimeter hole spacing, and least resistance line should be predetermined at their optimal levels, and for the secondary factors including charge concentration and detonation velocity, the values can be determined flexibly based on both the cost and operation conveniences. In practice, the lower the magnitude of over-/ underbreak, the better the quality of smooth blasting. With the specific geological conditions of this case, the optimum level of charging explosive is $0.15 \mathrm{~kg} / \mathrm{m}$, for perimeter hole spacing is $60 \mathrm{~cm}$, and for least resistance line is $55 \mathrm{~cm}$.

The cost-efficient numerical investigation method offers a promising alternative to well understand the influential factors that affect the quality of smooth blasting. Due to the complexity and uncertainties of geological conditions, the results obtained might vary with the specific site conditions. However, this work presents an efficient approach to quantitatively investigate the influential factors of smooth blasting, and it is believed to be beneficial for the optimization of parameter design of smooth blasting.

\section{Data Availability}

The data used to support the findings of this study are included within the article.

\section{Conflicts of Interest}

The authors declare that there are no conflicts of interest regarding the publication of this paper.

\section{Acknowledgments}

The financial support for this research project by the National Natural Science Foundation of China (nos. 41602308 and 41572299), the Zhejiang Provincial Natural Science Foundation of China under (no. LY20E080005), the Zhejiang Science and Technology Project (no. 2016C33033), and the Foundation of China Railway No.2 Engineering Group Co., Ltd. (no. 201218) was gratefully acknowledged.

\section{References}

[1] N. Innaurato, R. Mancini, and M. Cardu, "On the influence of rock mass quality on the quality of blasting work in tunnel driving," Tunnelling and Underground Space Technology, vol. 13, no. 1, pp. 81-89, 1998. 
[2] S. Zare and A. Bruland, "Comparison of tunnel blast design models," Tunnelling and Underground Space Technology, vol. 21, no. 5, pp. 533-541, 2006.

[3] S. K. Mandal and M. M. Singh, "Evaluating extent and causes of overbreak in tunnels," Tunnelling and Underground Space Technology, vol. 24, no. 1, pp. 22-36, 2009.

[4] Y. Kim and A. Bruland, "A study on the establishment of Tunnel Contour Quality Index considering construction cost," Tunnelling and Underground Space Technology, vol. 50, pp. 218-225, 2015.

[5] X. P. Li, J. H. Huang, Y. Luo, and P. P. Chen, "A study of smooth wall blasting fracture mechanisms using the Timing Sequence Control Method," International Journal of Rock Mechanics and Mining Sciences, vol. 92, pp. 1-8, 2017.

[6] K.-G. Hinzen, "Comparison of seismic and explosive energy in five smooth blasting test rounds," International Journal of Rock Mechanics and Mining Sciences, vol. 35, no. 7, pp. 957-967, 1998.

[7] E. Costamagna, C. Oggeri, P. Segarra, R. Castedo, and J. Navarro, "Assessment of contour profile quality in D\&B tunnelling," Tunnelling and Underground Space Technology, vol. 75, pp. 67-80, 2018.

[8] H. K. Verma, N. K. Samadhiya, M. Singh, R. K. Goel, and P. K. Singh, "Blast induced rock mass damage around tunnels," Tunnelling and Underground Space Technology, vol. 71, pp. 149-158, 2018.

[9] Q.-S. Liu, J. Wu, X.-P. Zhang et al., "Microseismic monitoring to characterize structure-type rockbursts: a case study of a TBM-excavated tunnel," Rock Mechanics and Rock Engineering, vol. 53, no. 7, pp. 2995-3013, 2020.

[10] K. Liu and B. Liu, "Optimization of smooth blasting parameters for mountain tunnel construction with specified control indices based on a GA and ISVR coupling algorithm," Tunnelling and Underground Space Technology, vol. 70, pp. 363-374, 2017.

[11] M. Khandelwal and M. Monjezi, "Prediction of backbreak in open-pit blasting operations using the machine learning method," Rock Mechanics and Rock Engineering, vol. 46, no. 2, pp. 389-396, 2012.

[12] G. R. Tripathy and I. D. Gupta, "Prediction of ground vibrations due to construction blasts in different types of rock," Rock Mechanics and Rock Engineering, vol. 35, no. 3, pp. 195-204, 2014.

[13] J. C. Li, H. B. Li, G. W. Ma, and Y. X. Zhou, "Assessment of underground tunnel stability to adjacent tunnel explosion," Tunnelling and Underground Space Technology, vol. 35, pp. 227-234, 2013.

[14] Z.-D. Cui, L. Yuan, and C.-L. Yan, "Water-silt composite blasting for tunneling," International Journal of Rock Mechanics and Mining Sciences, vol. 47, no. 6, pp. 1034-1037, 2010.

[15] L. X. Xie, W. B. Lu, Q. B. Zhang, Q. H. Jiang, G. H. Wang, and J. Zhao, "Damage evolution mechanisms of rock in deep tunnels induced by cut blasting," Tunnelling and Underground Space Technology, vol. 58, pp. 257-270, 2016.

[16] U. Nyström and K. Gylltoft, "Numerical studies of the combined effects of blast and fragment loading," International Journal of Impact Engineering, vol. 36, no. 8, pp. 995-1005, 2009.

[17] B. Jayasinghe, Z. Zhao, A. G. Teck Chee, H. Zhou, and Y. Gui, "Attenuation of rock blasting induced ground vibration in rock-soil interface," Journal of Rock Mechanics and Geotechnical Engineering, vol. 11, no. 4, pp. 770-778, 2019.
[18] A. K. Raina, A. K. Chakraborty, M. Ramulu, and J. L. Jethwa, "Rock mass damage from underground blasting, a literature review, and lab- and full scale tests to estimate crack depth by ultrasonic method," Fragblast, vol. 4, no. 2, pp. 103-125, 2000.

[19] D. Saiang and E. Nordlund, "Numerical analyses of the influence of blast-induced damaged rock around shallow tunnels in brittle rock," Rock Mechanics and Rock Engineering, vol. 42, no. 3, pp. 421-448, 2008.

[20] M. Ramulu, A. K. Chakraborty, and T. G. Sitharam, "Damage assessment of basaltic rock mass due to repeated blasting in a railway tunnelling project-a case study," Tunnelling and Underground Space Technology, vol. 24, no. 2, pp. 208-221, 2009.

[21] Z.-D. Cui, "Effect of water-silt composite blasting on the stability of rocks surrounding a tunnel," Bulletin of Engineering Geology and the Environment, vol. 70, no. 4, pp. 657-664, 2010.

[22] A. M. Benselama, M. J. William-Louis, F. Monnoyer, and C. Proust, "A numerical study of the evolution of the blast wave shape in tunnels," J Hazard Mater, vol. 181, no. 1-3, pp. 609-616, 2010.

[23] E. Hamdi, N. B. Romdhane, and J. M. Le Cléac'h, “A tensile damage model for rocks: application to blast induced damage assessment," Computers and Geotechnics, vol. 38, no. 2, pp. 133-141, 2011.

[24] Z. Zhao, Y. Zhang, and H. Bao, "Tunnel blasting simulations by the discontinuous deformation analysis," International Journal of Computational Methods, vol. 8, no. 2, pp. 277-292, 2011.

[25] L. F. Fan, X. W. Yi, and G. W. Ma, "Numerical manifold method (NMM) simulation of stress wave propagation through fractured rock mass," International Journal of Applied Mechanics, vol. 5, no. 2, 2013.

[26] R. Carrera-Cerritos, C. Ponce de León, J. Ledesma-García, R. Fuentes-Ramírez, and L. G. Arriaga, "Full factorial design applied to the synthesis of Pd-Ag nanobars by the polyol method and the perspective for ethanol oxidation," RSC Advances, vol. 4, no. 32, pp. 16632-16640, 2014.

[27] Z. Ge, Z. Gao, R. Sun, and L. Zheng, "Mix design of concrete with recycled clay-brick-powder using the orthogonal design method," Construction and Building Materials, vol. 31, pp. 289-293, 2012.

[28] C. Wang, R. Song, G. Wang, S. Zhang, X. Cao, and P. Wei, "Modifications of the HJC (Holmquist-Johnson-Cook) model for an improved numerical simulation of roller compacted concrete (RCC) structures subjected to impact loadings," Materials, vol. 13, no. 6, 2020.

[29] M. Cardu, R. Mancini, and C. Oggeri, "Ground vibration problems in the excavation of tunnels under small rock cover," in Proceedings of the SWEMP 2004-Symposium on Environmental Issues and Waste Management in Energy and Mineral Production, pp. 353-356, Antalya, Turkey, May 2004.

[30] T. J. Holmquist and G. R. Johnson, "A computational constitutive model for glass subjected to large strains, high strain rates and high pressures," in Proceedings of the 14th International Symposium on Ballistics, IEEE Press, Quebec, Canada, pp. 591-600, September 1993.

[31] Y. S. Tai, T. L. Chu, H. T. Hu, and J. Y. Wu, "Dynamic response of a reinforced concrete slab subjected to air blast load," Theoretical and Applied Fracture Mechanics, vol. 56, no. 3, pp. 140-147, 2011.

[32] N. Jiang and C. Zhou, "Blasting vibration safety criterion for a tunnel liner structure," Tunnelling and Underground Space Technology, vol. 32, pp. 52-57, 2012. 
[33] C. F. Zhao and J. Y. Chen, "Damage mechanism and mode of square reinforced concrete slab subjected to blast loading," Theoretical and Applied Fracture Mechanics, vol. 63-64, pp. 54-62, 2013.

[34] J. H. Yang, C. Yao, Q. H. Jiang, W. B. Lu, and S. H. Jiang, "2D numerical analysis of rock damage induced by dynamic insitu stress redistribution and blast loading in underground blasting excavation," Tunnelling and Underground Space Technology, vol. 70, pp. 221-232, 2017.

[35] H. Tang, Field Experimental and Theoretical Study on Blasting Wave Propagation Characteristics under Different Terrains, Chinese Academy of Sciences, Beijing, China, 2007, in Chinese.

[36] Z. L. Wang, H. Konietzky, and R. Y. Huang, "Elastic-plastichydrodynamic analysis of crater blasting in steel fiber reinforced concrete," Theoretical and Applied Fracture Mechanics, vol. 52, no. 2, pp. 111-116, 2009.

[37] Z. L. Wang, H. Konietzky, and R. F. Shen, "Coupled finite element and discrete element method for underground blast in faulted rock masses," Soil Dynamics and Earthquake Engineering, vol. 29, no. 6, pp. 939-945, 2009.

[38] C. Qi, S. Yang, L.-J. Yang, Z.-Y. Wei, and Z.-H. Lu, "Blast resistance and multi-objective optimization of aluminum foam-cored sandwich panels," Composite Structures, vol. 105, pp. 45-57, 2013.

[39] F. Dolce, M. Meo, A. Wright, M. French, and M. Bernabei, "Hybrid S2/carbon epoxy composite armours under blast loads," Applied Composite Materials, vol. 19, no. 3-4, pp. 349-362, 2011.

[40] C. Soutis, G. Mohamed, and A. Hodzic, "Modelling the structural response of GLARE panels to blast load," Composite Structures, vol. 94, no. 1, pp. 267-276, 2011.

[41] Z. Wang, Y. Li, and J. G. Wang, "A method for evaluating dynamic tensile damage of rock," Engineering Fracture Mechanics, vol. 75, no. 10, pp. 2812-2825, 2008.

[42] C. Soutis, G. Mohamed, and A. Hodzic, "Multimaterial arbitrary-Lagrangian-eulerian formulation for blast-induced fluid-structure interaction in fiber-metal laminates," AIAA Journal, vol. 50, no. 9, pp. 1826-1833, 2012.

[43] J. Shen, G. Lu, L. Zhao, and Z. Qu, "Response of curved sandwich panels subjected to blast loading," Journal of Performance of Constructed Facilities, vol. 25, no. 5, pp. 382-393, 2011.

[44] S. J. Pahos, "The ballistic response of cross-stiffened panels from a rocket-propelled grenade," Naval Engineers Journal, vol. 123, no. 1, pp. 55-65, 2011.

[45] X. Y. Wei, Z. Y. Zhao, and J. Gu, "Numerical simulations of rock mass damage induced by underground explosion," International Journal of Rock Mechanics and Mining Sciences, vol. 46, no. 7, pp. 1206-1213, 2009.

[46] C.-b. Zhou, P. Wang, Y.-j. Lei, and X.-p. Yin, "Optimization on cut-hole of mining tunnel excavation," Mining Science and Technology, vol. 19, no. 1, pp. 70-73, 2009, in Chinese.

[47] Z. Yingren, W. Yongfu, W. Cheng, and F. Xiating, "Stability analysis and exploration of failure law of jointed rock tunnel-seminor on tunnel stability analysis," Chinese Journal of Underground Space and Engineering, vol. 7, no. 4, pp. 649656, 2011, in Chinese. 